\title{
Involvement of Subcortical and Cortical Afferents to the Lateral Nucleus of the Amygdala in Fear Conditioning Measured with Fear-Potentiated Startle in Rats Trained Concurrently with Auditory and Visual Conditioned Stimuli
}

\author{
Serge Campeau and Michael Davis \\ Departments of Psychology and Psychiatry, Yale University School of Medicine and the Abraham Ribicoff Research \\ Facilities of the Connecticut Mental Health Center, New Haven, Connecticut
}

The goal of this work was to test the involvement, in fear conditioning, of afferents to the lateral nucleus of the amygdala originating from the auditory thalamus, auditory cortex, and perirhinal area. The acoustic startle reflex was used as the behavioral index of conditioning because it is reliably enhanced in the presence of a conditioned stimulus (CS) previously paired with a footshock. Auditory and visual CSs were used to assess the modality specificity of lesions to the above brain areas.

Pre- or posttraining lesions of the entire auditory thalamus including the ventral, dorsal, and medial divisions of the medial geniculate body, the posterior intralaminar nucleus, and the suprageniculate nucleus, completely blocked fear-potentiated startle to the auditory CS, but had no effect on fear-potentiated startle to the visual CS. Posttraining lesions mostly restricted to the ventral and dorsal divisions of the medial geniculate body specifically disrupted fear-potentiated startle to the auditory $\mathrm{CS}$. However, retralning in rats sustaining ventral and dorsal medial geniculate body lesions led to reliable fear-potentiated startle to the auditory CS. Posttraining lesions mostly restricted to the medial division of the medial geniculate body, posterior intralaminar, and suprageniculate nuclei did not disrupt fear-potentiated startle. These results indicate that the auditory thalamus is specifically involved, through either its direct or indirect amygdaloid afferents, in fear conditioning to auditory CSs.

Pre- or posttraining lesions mostly restricted to the primary auditory cortex did not reliably attenuate fear-potentiated startle to the auditory or visual CSs. Extensive posttraining lesions of the perirhinal area (including secondary auditory cortices), but not its rostral aspect alone, blocked fear-potentiated startle to both CSs. However, reliable po-

\footnotetext{
Received Aug. 30, 1994; revised Sept. 23, 1994; accepted Sept. 30, 1994

This research was supported by NIMH Grants MH-25642 and MH-47840, Research Scientist Development Award MH-00004 to Michael Davis, a grant from the Air Force Office of Scientific Research, and the State of Connecticut We thank Drs. Thomas Carew, Edward Kairiss, David McCormick, and Allan Wagner for insightful discussion of this research. Thanks are extended to Younglim Lee for her comments on an earlier draft of the manuscript. This work was submitted by S.C. to the Graduate School of Yale University in partia fulfillment of the requirements for a Ph.D. degree.

Correspondence should be addressed to Serge Campeau, Mental Health Research Institute, 205 Zina Pitcher Place, University of Michigan, Ann Arbor MI 48109-0720.

Copyright $(C) 1995$ Society for Neuroscience $0270-6474 / 95 / 152312-16 \$ 05.00 / 0$
}

tentiated startle was observed to both CSs following similarly extensive pretraining lesions of the perirhinal area. Because post- but not pretraining lesions of the perirhinal area blocked fear-potentiated startle nonspecifically, at least with regard to auditory and visual CSs, the results are consistent with the involvement of the perirhinal area in general memory functions such as information storage or retrieval. Alternatively, the secondary auditory and/or perirhinal cortices might function as multimodal sensory relays to the amygdala.

[Key words: medial geniculate, perirhinal, auditory cortex, acoustic startle]

Recent findings indicate that the basolateral complex of the amygdala, traditionally including the lateral, basolateral, and basal nuclei (De Olmos et al., 1985), is an essential link in the neural circuit mediating classical fear conditioning, at least for auditory and visual conditioned stimuli (LeDoux et al., 1990b; Sananes and Davis, 1992; Campeau and Davis, 1995). Anatomically, the necessity of the basolateral complex, and more particularly the lateral nucleus in fear conditioning, depends at least in part upon its relay function between various subcortical and cortical sensory areas and the central nucleus of the amygdala (see LeDoux et al., 1990a). In rats, subcortical afferents to the lateral nucleus of the amygdala originate from the thalamic medial division of the medial geniculate body (MGM), the posterior intralaminar nucleus (PIN), and the suprageniculate nucleus (SG; Veening, 1978b; Ottersen and Ben-Ari, 1979; Turner and Herkenham, 1981, 1991; LeDoux et al., 1984, 1985, 1987, 1990a, 1991a,b). These direct thalamo-amygdala projections are known to be involved in the processing of auditory, somatosensory, and even visual information, in the case of SG (Peschanski et al., 1981; LeDoux et al., 1985, 1987; Hicks et al., 1986). Cortical afferents to the lateral nucleus of the amygdala include the perirhinal (PRh), and secondary auditory cortices (Te2, Te3; Veening, 1978a; Wakefield, 1980; Turner and Herkenham, 1981, 1991; Ottersen, 1982; Turner and Zimmer, 1984; McDonald and Jackson, 1987; LeDoux et al., 1991a; Mascagni et al., 1993; Romanski and LeDoux, 1993b). The cortico-amygdala projections from $\mathrm{Te} 2$ and $\mathrm{Te} 3$, which have only been described recently, are mostly involved in auditory processing (McDonald and Jackson, 1987; LeDoux et al., 1991 a; Mascagni et al., 1993; Romanski and LeDoux, 1993b), showing high- to low-frequency responses in a rostral to caudal extension (Sally and Kelly, 1988). However, visual afferents to posterior $\mathrm{Te} 2$ have also been 
documented (Coleman and Clerici, 1980). The perirhinal cortex, defined here as in Paxinos and Watson (1986), receives mixed polymodal inputs, at least for auditory, visual, and possibly somatosensory information, based on anatomical (Dcacon ct al., 1983; see also Guldin and Markowitsch, 1983, for associative insular area), and electrophysiological evidence from cats and monkeys (Loe and Benevento, 1969; Fallon and Benevento, 1977; Robinson and Burton, 1980).

The involvement of the various afferents to the lateral nucleus of the amygdala in fear conditioning has usually been tested using auditory conditioned stimuli (CS). In rats, electrolytic or excitotoxic lesions of the entire auditory thalamus, including the ventral (MGV) and dorsal (MGD) divisions of the medial geniculate body, together with MGM, PIN, and SG, completely disrupt somatomotor and cardiovascular conditioned responses to auditory CSs (LeDoux et al., 1984, 1986a,b; Iwata et al., 1986).

Regarding more discrete auditory thalamic lesions, initial studies in rabbits suggested that MGM lesions produced unreliable attenuation of conditioned bradycardia to an auditory CS paired with shock (Jarrell et al., 1986a,b, 1987). However, these remaining "conditioned" bradycardiac responses observed in MGM lesioned rabbits following auditory CS-shock pairings were recently suggested to be "unconditioned" because similar bradycardiac responses are observed in MGM lesioned rabbits given unpaired auditory CS and shock presentations (McCabe et al., 1993). Thus, this outcome suggests that the MGM is essential for conditioned bradycardia. In rats, however, electrolytic lesions limited to MGM, PIN, and SG, do not disrupt somatomotor or cardiovascular conditioned responses (Romanski and LeDoux, 1992a). At the present time, it is not clear why different outcome were obtained in the study of Romanski and LeDoux with rats, and those of Jarrell, McCabe, and coworkers with rabbits, after relatively discrete lesions involving the MGM.

In all the studies reporting conditioning deficits after auditory thalamic lesions (LeDoux et al., 1984, 1986a,b; Iwata et al., 1986; McCabe et al., 1993), the specificity of the lesions upon the auditory modality has not been clearly established (but see LeDoux et al., 1986b, for instrumental aversive conditioning to visual discriminatory stimuli). This is important because as stated above, MGM, PIN, and SG, which were included in the total thalamic lesions of LeDoux and coworkers, are not only involved in auditory processing, but have also been implicated in somatosensory and visual processing. Thus, a primary goal of the following experiments was to evaluate the auditory specificity of subcortical thalamic lateral amygdala afferents by using both auditory and visual CSs in the same animals. In addition, because the results of prior studies were obtained exclusively with pretraining lesions, the observed deficits could have been produced by disruption of a somatosensory pathway (MGM, PIN) involved in the transmission of nociceptive information induced by electric shock stimuli, as suggested recently (Cruikshank et al., 1992). Hence, another goal of this work was to evaluate the effects of lesions both before and after training (when shocks are no longer presented). The effects of complete auditory thalamic lesions, as compared to lesions restricted to the direct thalamo-amygdala pathway (MGM, PIL, and SG) or to MGV and MGD (which provide auditory inputs to the amygdala only via a cortical relay; see below), were also measured. In the present studies, the MGD is defined as in Paxinos and Watson (1986), and excludes the adjacent SG, which provides

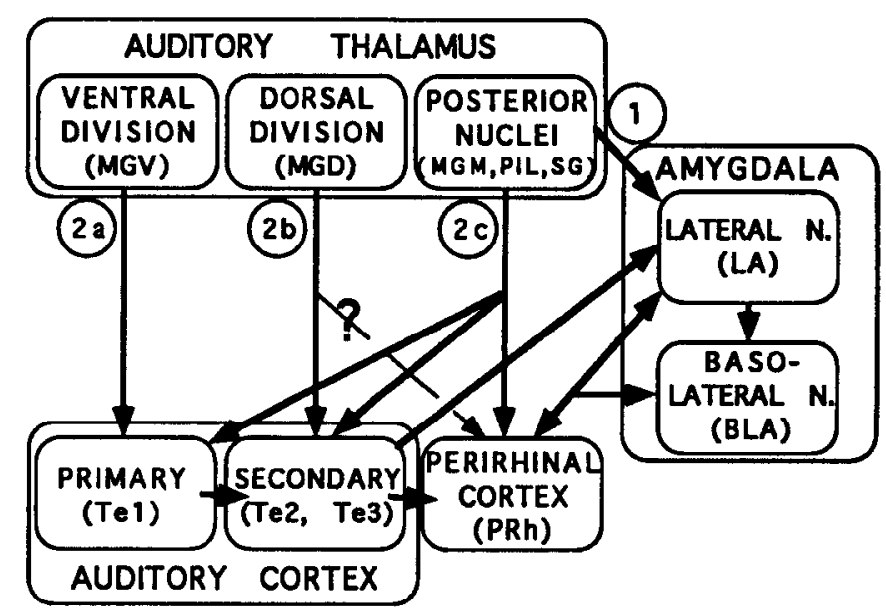

Figure 1. Schematic diagram of auditory afferents to the lateral nucleus of the amygdala. The direct thalamo-amygdala pathway $(I)$ originates from the posterior auditory thalamic nuclei. The thalamo-corticoamygdala pathway $(2 a, 2 b, 2 c)$ originates from all auditory thalamic subnuclei. Inputs from the ventral division of the medial geniculate body to the primary auditory cortex $(2 a)$ must be relayed to the secondary auditory cortex before reaching the lateral nucleus of the amygdala. The uncertainty of the existence of afferents to the perirhinal cortex from the dorsal division of the medial geniculate body is indicated by a question mark.

dircct subcortical projections to the amygdala, whereas the MGD does not (LeDoux et al., 1985).

With regard to cortical lateral amygdala afferents, pretraining lesions of $\mathrm{Te} 1, \mathrm{Te} 2$, and $\mathrm{Te} 3$ alone, or in combination with PRh, or even complete neodecortication, do not prevent fear conditioning to an auditory CS (DiCara et al., 1970; LeDoux et al., 1984; Romanski and LeDoux, 1992a,b). Similarly, pretraining auditory cortex lesions in rabbits do not disrupt bradycardiac conditioned responses to an auditory CS paired with shock (Jarrell et al., 1987; Teich et al., 1988). As discussed above, Te2, $\mathrm{Te} 3$, and the PRh provide afferent projections to the lateral nucleus of the amygdala; auditory inputs from $\mathrm{Te} 1$ can also reach the lateral nucleus via relays in $\mathrm{Te} 2$ or $\mathrm{Te} 3$ (see Fig. 1 for a schematic diagram of subcortical and cortical afferents to the lateral nucleus of the amygdala). Auditory thalamo-cortical relays involve afferents from all subdivisions of the medial geniculate body and surrounding posterior auditory thalamic nuclei projecting to either $\mathrm{Te} 1, \mathrm{Te} 2, \mathrm{Te} 3$, or PRh (Ryugo and Killackey, 1974; Deacon et al., 1983; LeDoux et al., 1985, 1991a; Winer and Larue, 1987; Roger and Arnault, 1989; Arnault and Roger, 1990; Clerici and Coleman, 1990; Romanski and LeDoux, 1993a). Thus, in rats, pretraining lesions limited to either $\mathrm{Te} 1$, Te2, Te 3 and PRh on the one hand, or MGM, PIN, and SG on the other hand, do not disrupt auditory fear conditioning, indicating that cortical or subcortical pathways are sufficient to mediate auditory fear conditioning. Combined pretraining lesions of both cortical and thalamic areas, however, produce severe auditory conditioning deficits (Romanski and LeDoux, 1992b), just as complete auditory thalamic lesions do (LeDoux et al., 1984, 1986a,b; Iwata et al., 1986). The specificity of these combined lesions upon auditory fear conditioning is not known.

In contrast to the studies by Dicara et al. (1970) and Romanski and LeDoux (1992a,b) in which pretraining cortical lesions extending to the perirhinal cortex did not disrupt auditory fear conditioning, relatively circumscribed posttraining electrolytic lesions to the anterior perirhinal cortex in rats blocked fear con- 
ditioning to a visual CS (Rosen et al., 1992). Similarly, many instances of instrumental aversive conditioning in auditory signaled avoidance tasks are disrupted by relatively extensive posttraining auditory cortical lesions usually cxtending to the insulartemporal cortex in cats, the homolog of the perirhinal cortex in rats (Guldin and Markowitsch, 1983; see Neff et al., 1975, for a review). The difference in outcome between the studies described by Neff et al. (1975) and Rosen et al. (1992), and those from DiCara et al. (1970) and Romanski and LeDoux (1992a,b), may arise from the use of posttraining lesions, which appear to consistently produce deficits (Neff el al., 1975; Rosen et al., 1992), versus pretraining lesions, which produce no detectable deficits (DiCara et al., 1970; Romanski and LeDoux, 1992a,b). Hence, an additional goal of the following experiments was to evaluate the involvement of cortical afferents to the lateral nucleus of the amygdala by testing the effects of lesions to Te1, or combined lesions to Te2, Te3, and PRh, both before and after training, upon fear conditioning to auditory and visual CSs. Conditioning was measured using the amplitude of the acoustic startlc rcflcx, which is reliably enhanced in the presence of a CS previously paired with footshock (Brown et al., 1951), a phenomenon now termed fear-potentiated startle. To assess the involvement of neurons as compared to fibers of passage in the lesioned areas, both electrolytic and neurotoxic lesions were routinely tested.

\section{Materials and Methods}

\section{Subjects}

Experimentally naive male albino Sprague--Dawley rats weighing 320$400 \mathrm{gm}$ (Charles River Co., Kingston, NY) were used. The rats were housed in wire cages $(17 \times 35 \times 45 \mathrm{~cm})$ in groups of two or three with water and laboratory chow continuously available, and maintained on a $12 \mathrm{hr}: 12 \mathrm{hr}$ light-dark cycle (lights on at 7:00 A.M.). Rats were acclimated to the colony rooms for $2-3$ weeks before experimental manipulation.

\section{Apparatus}

The equipment used was similar to that described previously (see Cassella and Davis, 1986, 1992, for details). Briefly, five separate stabilimeters were used, each consisting of a $8 \times 15 \times 15 \mathrm{~cm}$ Plexiglas and wire mesh cage suspended within a $25 \times 20 \times 20 \mathrm{~cm}$ heavy steel frame. The floor of each stabilimeter was composed of four stainless steel bars $(6.0 \mathrm{~mm}$ in diameter), spaced $20 \mathrm{~mm}$ apart (center to center), through which electric shocks could be delivered. Within the steel frame, the cage was compressed between four springs above and a $5 \times$ $5 \mathrm{~cm}$ rubber cylinder below, with an accelerometer (Endevco 2217E) located between the cage and the rubber cylinder. Cage movement resulted in displacement of the accelerometer, the output of which was amplified (Endevco model 104), digitized and stored on a Macintosh II computer. Startle amplitude was defined as the maximum accelerometer voltage that occurred during the first $200 \mathrm{msec}$ after startle stimulus onset. The stabilimeters were housed on two shelves within a ventilated, sound-attenuating chamber $(2.5 \times 2.5 \times 2 \mathrm{~m}$; Industrial Acoustic Co. $)$.

The startle stimuli were $50 \mathrm{msec}$ (rise-decay: $5 \mathrm{msec}$ ) bursts of white noise of variable intensity. Background white noise $(0-20 \mathrm{kHz})$ of 55 $\mathrm{dB}$ (SPL) was provided throughout all experiments. The auditory CS was produced by a white noise generator and band-pass filtered, with the low- and high-pass filters both set at $2 \mathrm{kHz}(24 \mathrm{~dB}$ /octave attenuation), at an intensity of $70 \mathrm{~dB}$ (SPL). Relatively low-frequency auditory CSs were previously found to produce reliable fear-potentiated startle (Campeau and Davis, 1992). The auditory CS was delivered by a speaker located approximately $70 \mathrm{~cm}$ in front of each cage. An $8 \mathrm{~W}$ fluorescent light bulb (rise-decay, $100 \mu \mathrm{sec} ; 800 \mathrm{ft}$ lamberts intensity), located approximately $5 \mathrm{~cm}$ behind, and at a level $5 \mathrm{~cm}$ above the grid floor of each startle cage, served as the visual CS. Each cage's grid floor could be electrified by constant current shock-generator scramblers at an intensity of $0.5 \mathrm{~mA}$ (see Cassella and Davis, 1986, for current derivation).

\section{Behavioral procedures}

Matching. On the first $2 \mathrm{~d}$ of all experiments, rats were placed in the stabilimeter cages and 5 min later presented with 30 startle stimuli at a $30 \mathrm{sec}$ interstimulus interval. Intensities of 90, 95, and $105 \mathrm{~dB}$ (SPL) were used with 10 startle stimuli at each intensity. Startle stimuli were presented in a balanced, irregular sequence with the restriction that each of the three intensities had to occur in every three trial blocks. The mean startle amplitude across the 30 startle stimuli on the last matching day was used to assign rats into several groups with similar means before training, or surgery.

Training. On the day after the last matching test, rats were placed in the stabilimeter cages and 5 min later presented with the first of ten 3.7 sec auditory CSs, mixed with 10 additional presentations of the $3.7 \mathrm{sec}$ visual CS. Auditory and visual CSs coterminated with footshock. The CSs were irregularly presented at a variable intertrial interval of 3.0 min (range, $1.5-4.5 \mathrm{~min}$ ), with the restriction that no more than three consecutive CSs of the same modality were presented. Training was conducted on each of 2 consecutive days, for a total of 20 presentations of each CS type.

Testing. Rats were placed back in the stabilimeters and 5 min later presented with 30 startle eliciting stimuli alone $(95 \mathrm{~dB})$. Thirty seconds following the last initial startle stimulus, 40 additional $95 \mathrm{~dB}$ startle stimuli were presented, consisting of 30 startle stimuli alone, 5 startle stimuli occurring $3.2 \mathrm{sec}$ after the onset of the $3.7 \mathrm{sec}$ auditory CS, and 5 startle stimuli occurring $3.2 \mathrm{sec}$ after the onset of the $3.7 \mathrm{sec}$ visual CS. The startle stimuli were presented at a fixed interstimulus interval of $30 \mathrm{sec}$, and the occurrence of each trial type was semirandom with the restriction that each block of eight trials contained six startle stimulus alone trials. one auditory CS trial, and one visual CS trial.

Posttraining lesion studies. Rats were first trained on each of 2 consecutive days, and given a potentiated startle test on the next day, as described above. On the basis of this test, rats showing greater than $50 \%$ startle potentiation to each CS modality (approximately $85 \%$ of all animals) were divided into unoperated, sham-operated or lesioned groups with similar levels of fear-potentiated startle to cach CS modality. Surgery was performed $24-48 \mathrm{hr}$ after the potentiated startle test. After a $10 \mathrm{~d}$ recovery period, rats were tested with the same initial fearpotentiated startle test.

Pretraining lesion studies. Rats were divided into unoperated, shamoperated or lesioned groups with similar startle responses on the basis of the matching test. Surgery was performed $24-48 \mathrm{hr}$ after matching. After a $7 \mathrm{~d}$ recovery period, rats were trained on each of 2 consecutive days and tested for fear-potentiated startle $24 \mathrm{hr}$ later. Thus, in both preand posttraining studies, the lesion-to-test interval was kept constant at $10 \mathrm{~d}$, but testing occurred either 1 or $10 \mathrm{~d}$ after training. This particular design was chosen because rats show similar fear-potentiated startle levels when tested from 1 to $30 \mathrm{~d}$ after training (Campeau et al., 1990).

Footshock sensitivity. Following pretraining lesion studies, rats were tested for their reactivity to footshock. They were placed in the stabilimeters and 5 min later presented with a train of 10 footshocks, of 0.5 $\mathrm{sec}$ duration, at a rate of $1 \mathrm{shock} / \mathrm{sec}$. Each rat received a total of 10 footshock trains, 2 at each of $0.2,0.4,0.6,0.8$, and $1.0 \mathrm{~mA}$ intensity, in an ascending/descending order. This procedure was performed to determine if lesions altered footshock sensitivity, at least as judged by this measure.

\section{Surgical procedures}

General. Rats were anesthetized by intraperitoneal injections of 400 $\mathrm{mg} / \mathrm{kg}$ of chloral hydrate (Sigma) dissolved in sterile saline $(0.9 \% \mathrm{NaCl})$ when electrolytic lesions were to be made. For ibotenic acid or NMDAinduced excitotoxic lesions, rats were anesthetized by intraperitoneal injection of $50 \mathrm{mg} / \mathrm{kg}$ of Nembutal ( $\Lambda$ bbott). Cortical aspirations were made under Halothane anesthesia to permit quick recovery after decortications. Rats were placed in a Kopf stereotaxic instrument equipped with blunt earbars, an incision of the skin overlying the skull was made, and small burr holes were drilled through the skull to allow penetration of electrodes or injectors. Bilateral lesions were performed in all experiments. Following the surgical procedures, the scalp incision was closed with surgical stainless steel clips, and rats were kept warm and under observation until recovery from anesthesia. They were subsequently housed two per cage to minimize isolation stress.

Electrolytic lesions. Electrolytic lesions were made with stainless steel electrodes $(0.25 \mathrm{~mm}$ in diameter) insulated except for $0.5 \mathrm{~mm}$ of the tip. A constant current source generated DC anodal current for all 
electrolytic lesions at an intensity of $0.1 \mathrm{~mA}$. Sham electrolytic lesions consisted of lowering the electrode $1.0 \mathrm{~mm}$ above the ventral lesion coordinate without passing current. All coordinates are in reference to the flat skull system of Paxinos and Watson (1986). If disruption of fear-potentiated startle was obtained with electrolytic lesions, the effects of excitotoxic lesions were evaluated in additional rats.

Excitotoxic lesions. Neuronal cell loss was induced by ibotenic acid of $\mathrm{N}$-methyl-D-aspartic acid (Sigma), dissolved in sodium phosphate

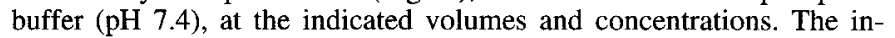
jector (Hamilton 1 or $2 \mu \mathrm{l}$ syringes) was lowered into the brain and left in place $5 \mathrm{~min}$ before and $10 \mathrm{~min}$ after each injection. The rate of infusion was $0.05 \mu \mathrm{l} / \mathrm{min}$. Sham surgeries involved the same manipulations except that only the vehicle solution (sodium phosphate buffer) was injected.

Lesions of the auditory thalamus. Posttraining lesions of the entire auditory thalamus were performed on 16 rats by passing current for 60 $\mathrm{sec}$ at $5.2 \mathrm{~mm}$ posterior, $3.3 \mathrm{~mm}$ lateral, and $6.8 \mathrm{~mm}$ ventral, and at 6.4 $\mathrm{mm}$ posterior, $3.3 \mathrm{~mm}$ lateral, and $6.8 \mathrm{~mm}$ ventral. Unoperated $(n=9)$ and sham-operated $(n=8)$ rats served as controls. Additional posttraining excitotoxic lesions of the entire auditory thalamus were performed on 15 rats by injecting $0.3 \mu \mathrm{l}$ of a $15 \mu \mathrm{g} / \mu \mathrm{l}$ solution of ibotenic acid at $5.2 \mathrm{~mm}$ posterior, $3.3 \mathrm{~mm}$ lateral, and $6.8 \mathrm{~mm}$ ventral, and at 6.5 $\mathrm{mm}$ posterior, $3.2 \mathrm{~mm}$ lateral, and $6.8 \mathrm{~mm}$ ventral to bregma. Unoperated $(n=10)$ and sham-operated $(n=10)$ rats served as controls Lesions similar to the ones described above for posttraining electrolytic lesions were given to 11 additional rats before training. Additional unoperated $(n=7)$ and sham-operated $(n=7)$ rats served as controls.

Extensive pilot work indicated that more confined lesions could be obtained by NMDA as compared to ibotenic acid infusion in the auditory thalamus. Thus, excitotoxic lesions of the ventral and dorsal divisions of the medial geniculate body were performed on 16 rats by injecting a $20 \mu \mathrm{g} / \mu \mathrm{l}$ solution of NMDA in a volume of $0.05 \mu \mathrm{l}$ at 5.0 $\mathrm{mm}$ posterior, $3.4 \mathrm{~mm}$ lateral, and $6.4 \mathrm{~mm}$ ventral, with a second injection of a volume of $0.08 \mu \mathrm{l}$ at $6.1 \mathrm{~mm}$ posterior, $3.4 \mathrm{~mm}$ lateral, and $6.2 \mathrm{~mm}$ ventral. Lesions of the posterior auditory thalamic nuclei were performed on 16 additional rats by injecting a $20 \mu \mathrm{g} / \mu \mathrm{l}$ solution of NMDA in a volume of $0.05 \mu \mathrm{l}$ at $5.1 \mathrm{~mm}$ posterior, $2.8 \mathrm{~mm}$ lateral, and $6.9 \mathrm{~mm}$ ventral, with a second injection of a volume of $0.08 \mu \mathrm{l}$ at $6.1 \mathrm{~mm}$ posterior, $2.8 \mathrm{~mm}$ lateral, and $6.9 \mathrm{~mm}$ ventral. Sham-operated rats $(n=10)$ served as controls. Three days after the postlesion fearpotentiated startle test, rats were retrained and retested with procedures similar to those used prior to lesions.

Lesions of the primary auditory cortex. Cortical lesions aimed at the primary auditory cortex were attempted in 15 rats by subpial aspiration via a small Pasteur pipette with a $90^{\circ}$ angled tip connected to a vacuum, using a direct approach of the temporal cortex exposed by removing an approximately $7 \mathrm{~mm} \times 4 \mathrm{~mm}$ flap of the overlying skull. Upon completion of tissue removal, the wound was packed with gelfoam previously soaked in sterile saline. The rats were then given multiple injections of lidocaine around the wound area, one injection of antibiotics, and anesthesia was discontinued. Sham lesions $(n=12)$ consisted of removing the skull overlying the same arca as in the lesioned animals, without performing tissue aspirations. Unoperated rats $(n=12)$ were also included in this study. Additional rats $(n=16)$ were given pretraining aspirations similar to the ones described above. Unoperated (n $=13)$ and sham-operated $(n=12)$ rats served as controls. Posttraining excitotoxic lesions aimed at the primary auditory cortex were performed in 16 additional rats by injecting a $20 \mu \mathrm{g} / \mu \mathrm{l}$ solution of NMDA in a volume of $0.22 \mu \mathrm{l}$ at $4.0 \mathrm{~mm}$ posterior, $6.4 \mathrm{~mm}$ lateral, and $5.2 \mathrm{~mm}$ ventral, and at $5.6 \mathrm{~mm}$ posterior, $6.6 \mathrm{~mm}$ lateral, and $5.4 \mathrm{~mm}$ ventral. Unoperated $(n=10)$ and sham-operated rats $(n=13)$ served as controls.

Lesions of the secondary auditory and perirhinal cortices. In an at tempt to first replicate the results of Rosen et al. (1992), initial posttraining lesions of the anterior perirhinal area (the anterior perirhinal cortex including cortical tissue dorsal to it) were tested. These lesions $(n=15)$ were performed electrolytically by passing current for $50 \mathrm{sec}$ at 1.8 and $3.0 \mathrm{~mm}$ posterior to bregma, each being $6.5 \mathrm{~mm}$ lateral and $8.1 \mathrm{~mm}$ ventral. Sham-operated $(n=11)$ rats served as controls. Posttraining excitotoxic lesions aimed at the anterior perirhinal area were performed on nine rats by injecting a $20 \mu \mathrm{g} / \mu \mathrm{l}$ solution of NMDA in a volume of $0.22 \mu \mathrm{l}$ at $2.7 \mathrm{~mm}$ posterior, $6.3 \mathrm{~mm}$ lateral, and $7.8 \mathrm{~mm}$ ventral. Unoperated $(n=6)$ and sham-operated $(n=6)$ rats served as controls. Posttraining excitotoxic lesions aimed at the perirhinal area in most of its rostro-caudal extent were performed on 23 rats by injecting a $20 \mu \mathrm{g} / \mu \mathrm{l}$ solution of NMDA in a volume of $0.22 \mu \mathrm{l}$ at $2.0 \mathrm{~mm}$ postcrior, $6.2 \mathrm{~mm}$ lateral, and $7.8 \mathrm{~mm}$ ventral, and volumes of $0.12 \mu \mathrm{l}$ at $4.5 \mathrm{~mm}$ posterior, $6.5 \mathrm{~mm}$ lateral, and $7.7 \mathrm{~mm}$ ventral, and $5.5 \mathrm{~mm}$ posterior, $6.6 \mathrm{~mm}$ lateral, and $7.6 \mathrm{~mm}$ ventral. Unoperated $(n=10)$ and sham-operated $(n=12)$ rats served as controls. Similar pretraining excitotoxic lesions of the entire perirhinal area were performed in 20 additional rats, including sham-operated $(n=16)$ and unoperated $(n=$ 12) controls.

\section{Histology}

At the end of the experiments, lesioned rats were anesthetized with an overdose of chloral hydrate and perfused with physiological saline followed by $10 \%$ buffered formalin phosphate. Brains were removed and stored in a solution of $30 \%$ sucrose in formalin for at least $2 \mathrm{~d}$. Brains were sectioned in a cryostat, where every fifth $40 \mu \mathrm{m}$ section in the lesioned area was placed on gelatin coated slides. After drying, the slides were stained with cresyl violet in the case of electrolytic lesions, or by the Kluver-Barrera method in the case of most excitotoxic lesions, to assess separately damage to cell bodies versus fibers of passage.

\section{Data reduction and statistical analysis}

The lesions were reconstructed on plates photocopied from the rat brain atlas of Paxinos and Watson (1986). Inclusion of rats in statistical analyses was strictly based on the adequacy of the lesions, without knowledge of the behavioral data of individual rats. Criteria for adequate lesions included bilateral damage of the area investigated throughout most of its extent, with incomplete and inconsistent damage of surrounding areas.

The initial 30 startle stimuli alone were used to habituate the rats to the acoustic startle stimuli and were not used for statistical analysis. Mean startle amplitudes were computed for the startle stimulus alone trials and the auditory and visual CS trials, respectively, for each rat. In addition, the mean startle amplitude on the startle stimulus alone trials was subtracted from the mean startle amplitude on the respective auditory and visual CS trials, providing a difference score for each CS modality, for each rat. Repeated-measures ANOVAs were first conducted on the mean startle amplitude data, to detect significant levels of fear-potentiated startle (trial type effect), and possible interactions with treatment (surgical conditions). Because the detection of significant interactions mainly reflects group differences between their respective startle stimulus alone trial means and auditory or visual CS trial means, these interactions were further analyzed by carrying out additional oneway ANOVAs on difference scores for each CS modality. A main effect of a one-way ANOVA on difference scores is numerically identical to the interaction term obtained from mean startle amplitude data computed for each CS modality, bul multiple mean comparisons are easier to visualize graphically and to compute using the difference score data. However, difference score analyzes were performed only in cases where no reliable effects had been obtained after an initial one-way ANOVA was performed on startle stimulus alone trials (i.e., no group differences could be attributed merely to changes in startle responsiveness). These analyses were complemented, when required, by post hoc multiple mean comparisons (Tukey HSD or Newman-Keuls) or $t$ tests.

For the shock-induced activity test, mean activity was computed by averaging activity across the 10 consecutive shock presentations for each intensity. The results of the ascending and descending shock series were further averaged for each shock intensity. Standard repeated-measures or one-way ANOVAs, complemented, when required, by $t$ tests, were then conducted.

\section{Results}

\section{Lesions of the entire auditory thalamus}

From the 16 rats undergoing posttraining electrolytic lesions of the entire auditory thalamus, three were excluded from the study because they sustained incomplete bilateral damage to MGM and PIN. In the other rats $(n=13)$, the lesions destroyed MGV, MGD, MGM, PIL, and SG. Inconsistent damage to the anterior pretectal nucleus, the lateral posterior nuclei, the lateral geniculate nuclei, the posterior thalamic nuclcus, the subparafascicular thalamic nucleus, the dorsomedial division of the substantia nigra, and the brachium of the inferior colliculus were also obtained. Histological reconstructions of the smallest and largest 

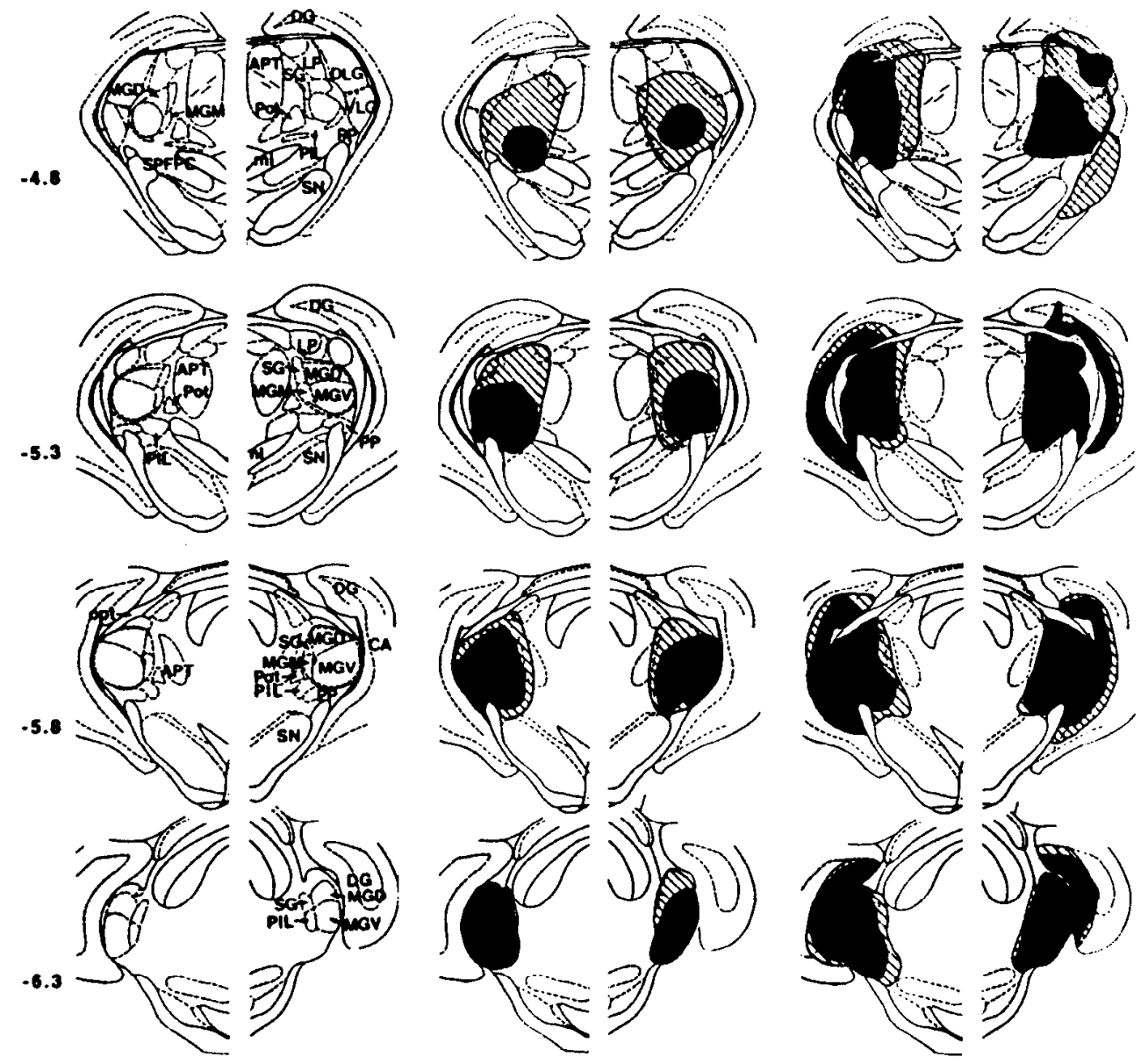

Figure 2. Histological reconstructions of the smallest (black) and largest (hatched) electrolytic (center) and ibotenic acid (right) lesions aimed at the entire auditory thalamus. Serial coronal plates through the extent of the auditory thalamus are shown on the left (the negative numbers to the left indicate posterior distance from bregma; adapted from Paxinos and Watson, 1986). The lateral aspects of each side of the brain with medial aspects reSee Appendix for abbreviations. electrolytically induced auditory thalamic lesions sustained by animals retained in this study are shown in Figure 2. The upper panel of Figurc 3 illustrates that complete posttraining electrolytic lesions of the auditory thalamus selectively disrupted fearpotentiated to the auditory, but not to the visual CS [trial type $\times$ treatment condition interaction, $F(4,54)=5.10, p<0.001]$. The ANOVA on startle stimulus alone trials indicated no treatment effect, $F(2,27)=0.04, p>0.05$. A reliable treatment condition effect was found on the auditory CS difference scores, $F(2,27)-13.75, p<0.001$, but not on the visual CS difference scores, $F(2,27)=1.01, p>0.05$. Rats sustaining auditory thalamic lesions had significantly lower potentiated startle to the auditory $\mathrm{CS}$ than the unoperated and sham-operated rats (all $p$ values $<0.05$ ). Furthermore, the lesioned group showed no evidence of potentiation to the auditory $\operatorname{CS}, t(12)=0.61, p>$ 0.05 , but significant potentiation to the visual $\mathrm{CS}, t(13)=3.83$, $p<0.002$. This specific disruption of fear-potentiated startle to the auditory CS cannot be explained by weaker conditioning in the lesioned rats, because the prelesion test indicated no differences between potentiation levels, $F(4,54)=0.18, p>0.05$ (data not shown).

From the 15 rats undergoing ibotenic acid lesions, four rats had significant bilateral cell sparing in MGV, MGD, MGM, or PIL, so these rats were excluded from further analyses. In the remaining rats $(n=11)$, the ibotenic acid lesions were typically similar to those produced electrolytically, but with increased damage to the lateral geniculate nuclei and hippocampal formation, as shown from the histological reconstructions of the smallest and largest lesions (Fig. 2). The middle panel of Figure
3 indicates that ibotenic acid lesions of the entire auditory thalamus also selectively disrupted potentiated startle to the auditory CS [trial type $\times$ treatment condition interaction, $F(4,56)=3.99$, $p<0.006]$. The ANOVA on startle stimulus alone trials indicated no treatment effect, $F(2,28)=1.21, p>0.05$. However, the lesioned rats were reliably different from the control rats on auditory CS difference scores, $F(2,28)=11.36, p<0.001$, but not on the visual CS difference scores, $F(2,28)=2.10, p>$ 0.05 . The lesioned rats had significantly lower potentiated startle levels than the unoperated or sham-operated rats ( $p$ values < 0.05 ). The lesioned group showed no reliable potentiation to the auditory CS, $t(10)=2.04, p>0.05$, but significant fear-potentiated startle to the visual $\mathrm{CS}, t(10)=6.19, p<0.001$. This again could not be attributed to weaker fear-potentiated startle in the group of rats that were to receive lesions, because all groups showed comparable potentiated startle levels prior to surgery [trial type $\times$ treatment condition, $F(4,56)=0.37, p>0.05$; data not shown].

From the 11 rats that underwent complete pretraining electrolytic lesions of the auditory thalamus, four rats had incomplete damage of the posterior auditory thalamic nuclei, and were thus excluded from the remaining analyses. In the other rats $(n=7)$, the electrolytic lesions performed prior to training were similar to the ones described above for rats sustaining posttraining lesions. The lower panel of Figure 3 shows that pretraining lesions of the entire auditory thalamus selectively disrupted fear-potentiated startle to the auditory CS, as observed with posttraining lesions [trial type $\times$ treatment condition interaction, $F(4,36)=$ 2.94, $p<0.03$ ]. The ANOVA on startle stimulus alone trials 


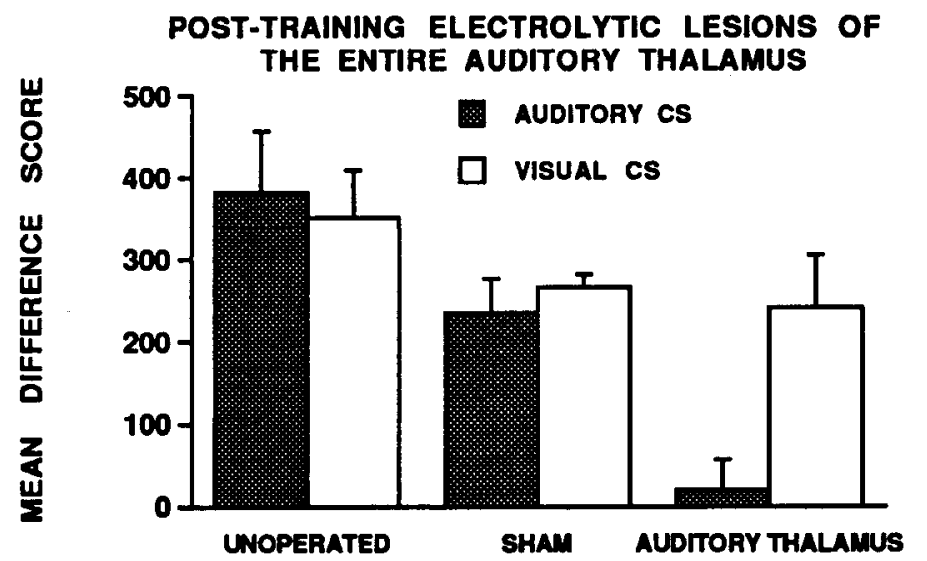

(9) (8)

TREATMENT CONDITION

(13)
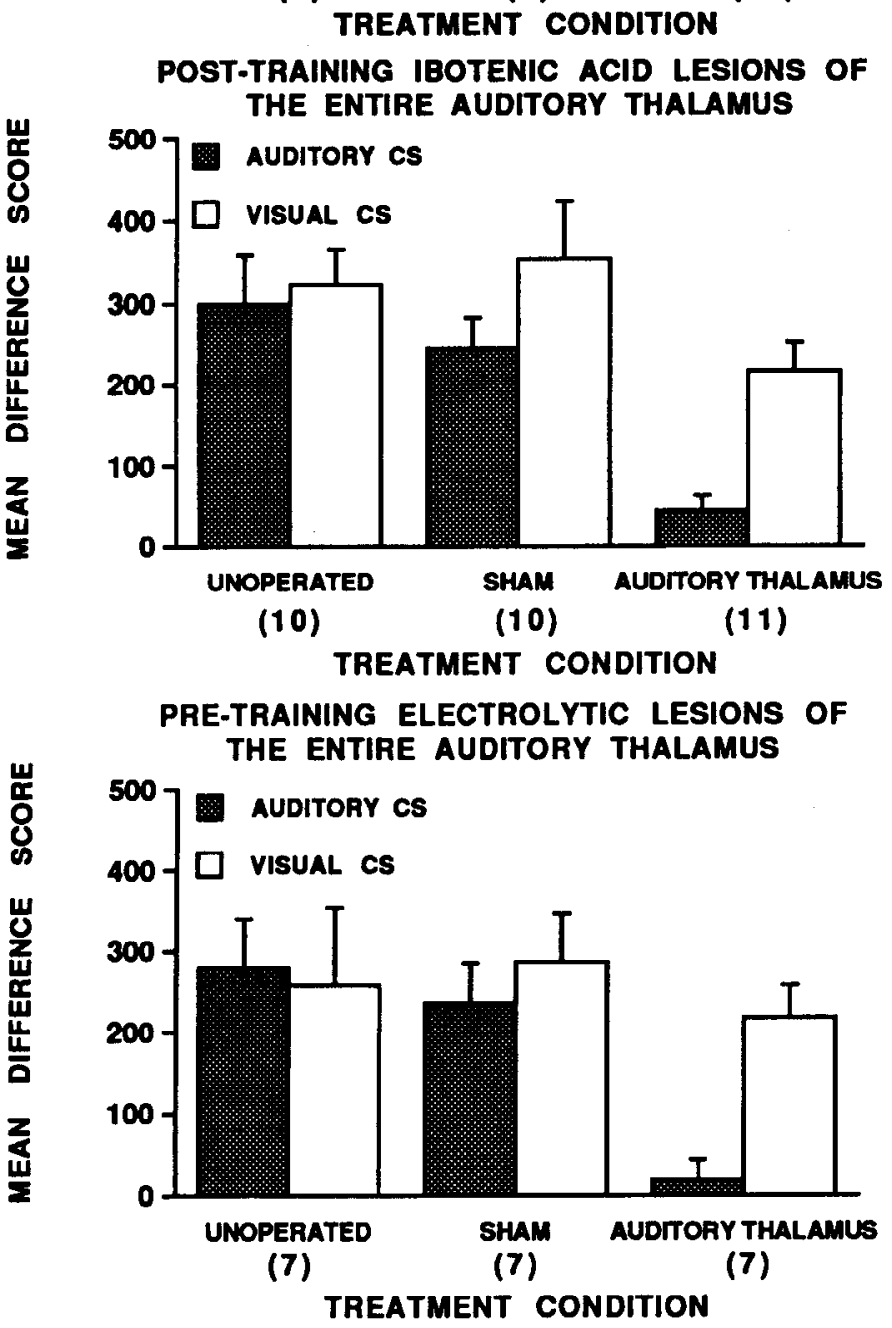

Figure 3. Mean difference scores $(+$ SEM) from auditory and visual CS trials for animals sustaining posttraining electrolytic (upper panel), ibotenic acid (middle panel), or pretraining electrolytic (lower panel) lesions of the entire auditory thalamus. Mean amplitude startle on the startle stimulus alone trials was 335.0 for unoperated rats, 358.3 for sham-operated rats, and 342.9 for rats sustaining posttraining lesions of the entire auditory thalamus. Mean amplitude startle on the startle stimulus alone trials was 241.1 for unoperated rats, 305.5 for sham-operated rats, and 241.8 for rats sustaining posttraining ibotenic acid lesions of the entire auditory thalanus. Mean amplitude startle on the startle stimulus alone trials was 323.0 for unoperated rats, 356.1 for sham-operated rats, and 319.4 for rats sustaining pretraining electrolytic lesions of the entire auditory thalamus. indicated no treatment effect, $F(2,18)=0.13, p>0.05$. A reliable treatment condition effect was obtained for the auditory $\mathrm{CS}, F(2,18)=8.50, p<0.003$, but not for the visual CS difference scores, $F(2,18)=0.24, p>0.05$. The auditory thalamic lesioned rats showed reliably lower potentiation than the unoperated and sham-opcrated animals, respectivcly (all $p$ valucs $<$ 0.05 , Tukey). These lesioned rats demonstrated significant startle potentiation to the visual $\mathrm{CS}, t(6)=5.57, p<0.001$, but not to the auditory CS, $t(6)=0.80, p>0.05$. This selective auditory disruption is not likely to be the result of lower shock reactivity in lesioned rats, because no reliable treatment condition effect on shock reactivity, $F(2,18)=2.45, p>0.05$, or of a treatment condition $\times$ shock intensity interaction, $F(8,72)=1.70, p>$ 0.05 , were obtained (see Table 1 ).

\section{Lesions of different subdivisions of the auditory thalamus}

From the 16 rats that were given NMDA lesions aimed at MGV and MGD, six rats only had unilateral or incomplete bilateral cell loss. From the 16 rats that were given NMDA lesions aimed at MGM, PIL, and SG, eight rats had unilateral or bilateral cell sparing of the MGM, PIL, or SG. These rats were left out of the remaining analyses. Reconstructions of the smallest and largest lesions of MGV and MGD or of MGM, PIL and SG, for the animals included in this experiment $(n=17)$, are presented in Figure 4. As shown in the upper panel of Figure 5, posttraining NMDA lesions of MGV and MGD specifically disrupted fearpotentiated startle to the auditory CS [trial type $x$ treatment condition interaction, $F(4,48)=4.41, p<0.005$ ]. Imporlantly, lesions of MGM, PIL, and SG did not disrupt fear-potentiated startle. This impression was supported by a reliable treatment condition effect on auditory CS difference scores, $F(2,24)=$ 5.73, $p<0.01$, where MGV and MGD lesioned rats were significantly different from the shams, $t(18)=3.89, p<0.001$, and posterior auditory thalamic lesioned rats, $t(15)=2.84, p<$ 0.02 . Importantly, there was no difference between the auditory difference scores of the sham and MGM, PIL, and SG lesioned rats $(p>0.05)$. A reliable effect was obtained on the visual CS difference scores, $F(2,24)=4.21, p<0.05$, but only because the rats sustaining posterior auditory thalamic lesions showed significantly greater potentiation than the MGV and MGD lesioned rats, $t(15)=2.61, p<0.02$. There was no difference between the visual CS difference scores of the sham and MGV and MGD lesioned rats, $t(18)=1.43, p>0.05$. Sham-operated and posterior auditory thalamic lesioned rats were reliably potentiated on the auditory and visual CS trials ( $p$ values $<0.05$ ). However, animals with MGV and MGD lesions did not show potentiation to the auditory $\mathrm{CS}, t(9)=1.83, p>0.05$, but demonstrated reliable fear-potentiation on visual CS trials, $t(9)=$ $4.42, p<0.005$. The specific disruption of fear-potentiated startle to the auditory CS in the group sustaining NMDA lesions of MGV and MGD, compared to the sham-operated or MGM, PIL, and SG lesioned rats, could not be attributed to different responsiveness to the startle stimulus, $F(2,24)=0.24, p>0.05$, nor to different potentiated startle levels between the treatment conditions prior to the lesions [trial type $\times$ treatment condition interaction, $F(4,48)=0.58, p>0.05$; data not shown].

The lower panel of Figure 5 also indicates that retraining in MGV and MGD lesioned rats produced relatively high levels of fear-potentiated startle to both CS modalities, as no trial type $x$ treatment condition interaction was detected $(p>0.05)$. 
Table 1. Footshock-induced reactivity (SEM) in animals sustaining lesions of different structures

\begin{tabular}{lrlllr}
\multicolumn{7}{l}{ Shock intensity (mA) } & & \\
\cline { 2 - 6 } Treatment & 0.2 & 0.4 & 0.6 & 0.8 & 1.0 \\
\hline Auditory thalamus & & & & \\
$\quad$ Unoperated & $135.4(47.6)$ & $480.9(67.5)$ & $835.7(86.0)$ & $897.4(91.8)$ & $1019.6(67.7)$ \\
$\quad$ Sham & $128.1(37.1)$ & $441.0(67.4)$ & $596.1(62.8)$ & $819.4(88.9)$ & $980.1(57.3)$ \\
$\quad$ Electrolytic & $63.0(31.2)$ & $306.0(16.2)$ & $527.6(69.3)$ & $755.6(45.8)$ & $897.4(70.7)$ \\
Perirhinal area & & & & & \\
$\quad$ Sham & $99.3(31.5)$ & $650.6(93.5)$ & $1171.6(175.9)$ & $1462.7(178.6)$ & $1730.5(165.2)$ \\
NMDA & $131.1(40.4)$ & $440.0(84.8)$ & $1003.1(145.1)$ & $1443.8(128.7)$ & $1614.7(106.6)$ \\
\hline
\end{tabular}

\section{Auditory cortex lesions}

From the 15 rats undergoing posttraining auditory cortical aspirations, five rats sustained unilateral or bilateral damage extending below the rhinal fissure, sometimes extending to the adjacent lateral nucleus of the amygdala, and two additional rats had significant sparing of the primary auditory area. These rats were excluded from subsequent analyses. The other rats $(n=$ 8) typically had near complete bilateral damage of the primary auditory cortex, and variable but incomplete damage to secondary auditory cortices, primary and secondary somatosensory cortices, and secondary visual cortex. All rats were observed to sustain consistent and significant cellular loss in the ventral division of the medial geniculate body, further indicating significant damage to the primary auditory cortex. Reconstructions of the smallest and largest cortical ablations are presented in Figure 6. The apparent attenuation of potentiated startle to either the auditory or visual CSs in rats decorticated after training shown in the upper panel of Figure 7 was not statistically reliable [trial type $\times$ treatment condition interaction, $F(4,58)=1.80, p>$ $0.05]$. Additional ANOVAs on auditory or visual CS difference scores did not reveal any treatment condition effects (all $p$ values $>0.05$ ). Each treatment condition displayed significant fear-potentiated startle to the auditory and visual CSs (all $p$ values $<$ 0.05).

From the 16 rats undergoing posttraining NMDA-induced lesions of the auditory cortex, five rats had incomplete bilateral cell loss in the primary auditory cortical area, and were excluded from the remaining analyses. In the other rats $(n=11)$, the
Figure 4. Histological reconstructions of the smallest (black) and largest (hatched) NMDA lesions aimed at the ventral and dorsal divisions of the medial geniculate body (center), or the posterior auditory thalamic nuclei (right). Serial coronal plates through the extent of the auditory thalamus are shown on the left. The lateral aspects of each side of the brain with medial aspects removed are shown to conserve space.
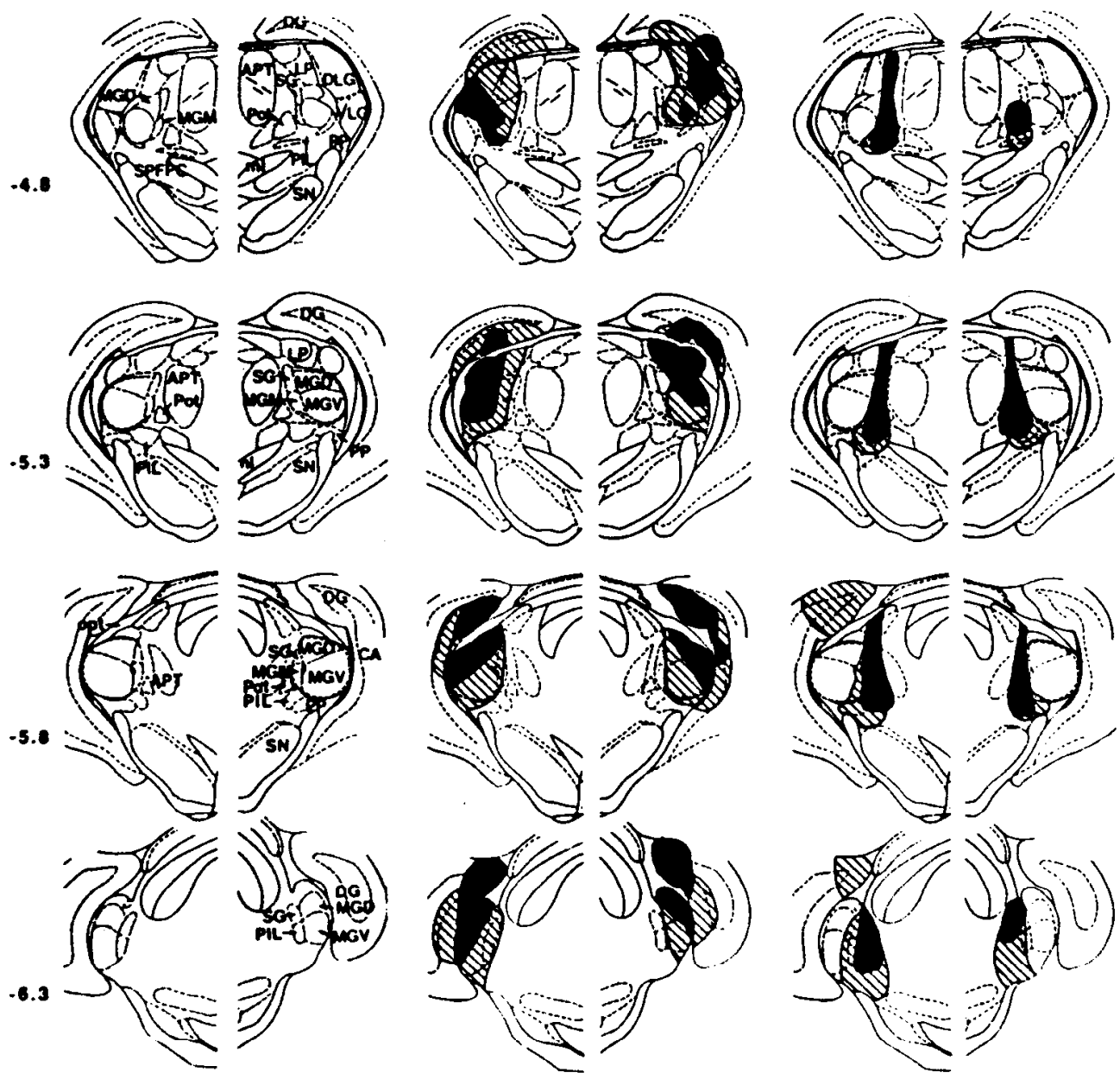

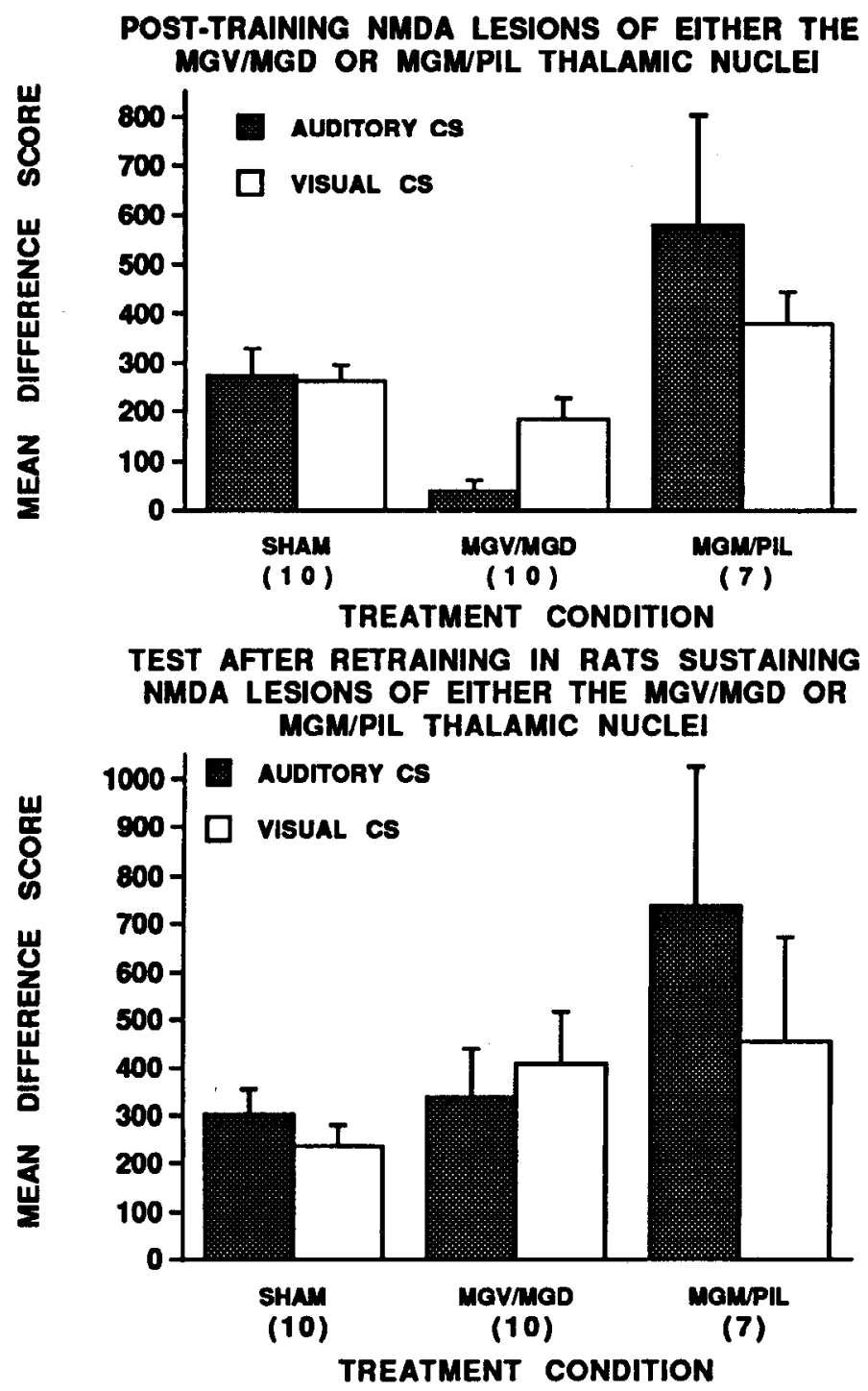

Figure 5. Mean difference scores (+SEM) from auditory and visual CS trials for animals sustaining posttraining lesions (upper panel) of different subdivisions of the auditory thalamus, which were retrained after the initial test (lower panel). Mean amplitude startle on the startle stimulus alone trials was 321.2 for sham-operated, 310.8 for rats sustaining postlraining NMDA lesions of the MGV/MGD, and 363.9 for rats sustaining NMDA lesions of the posterior auditory thalamic nuclei (MGM/PIL/SG). Mean amplitude startle on the startle stimulus alone trials was 281.4 for sham-operated, 303.0 for rats sustaining NMDA lesions of the MGV/MGD, and 415.3 for rats sustaining NMDA lesions of the posterior auditory thalamic nuclei (MGM/PIL/SG) after retraining.

excitotoxic lesions were relatively limited to auditory cortical areas, avoiding for the most part visual and somatosensory cortices, unlike the more extensive damage observed after aspiration lesions. Reconstructions of the smallest and largest NMDAinduced lesions of the auditory cortex are presented in Figure 6. As with aspiration lesions, the middle panel of Figure 7 also shows that posttraining NMDA-induced auditory cortex lesions did not reliably attenuate fear-potentiated startle [trial type $X$ treatment condition interaction, $F(4,28)-1.76, p>0.05]$. No reliable treatment condition effect was found for the auditory CS difference scores, $F(2,31)=0.80, p>0.05$, although this was reliable for the visual difference scores, $F(2,31)=4.30, p$
$<0.05$, because of a difference between the unoperated and auditory decorticated rats $(p<0.05)$, but not between the shamoperated and auditory decorticated rats $(p>0.05)$. Fear-potentiated startle to the auditory and visual CSs was reliable in all treatment conditions (all $p$ values $<0.05$ ).

From the 16 rats undergoing pretraining cortical aspirations, five rats had large lesions extending to the rhinal sulcus and lateral nucleus of the amygdala, and five additional rats were found to have sparing of the primary auditory cortex dorsally. These rats were excluded from further analyses. The extent of the lesions in the remaining six rats was similar to that described above for rats sustaining posttraining cortical aspirations. As indicated in the lower pancl of Figure 7, no differences between the different treatment conditions were obtained [trial type $\times$ treatment condition interaction, $F(4,56)=0.07, p>0.05]$. All treatment conditions demonstrated reliable potentiated startle to the auditory and visual CSs (all $p$ values $<0.05$ ).

\section{Lesions of the anterior perirhinal area}

From the 15 rats undergoing posttraining electrolytic lesions of the anterior perirhinal area, the lesions missed the ventral perirhinal area in four rats, two rats had relatively extensive lateral amygdala damage, and two additional rats had incomplete bilateral perirhinal area lesions. These rats were excluded from further analyses. In the other rats $(n=7)$, the lesions invaded all aspects of the perirhinal cortex, including ventral, lateral, medial, and dorsal aspects, and included significant portions of the secondary auditory and somatosensory cortices. These electrolytic lesions also abutted the external capsule and lateral nucleus of the amygdala, without, however, significantly damaging this nucleus. Reconstructions of the smallest and largest anterior perirhinal area lesions are presented in Figure 8. The upper panel of Figure 9 shows that relatively complete lesions of the anterior perirhinal cortical area appeared to disrupt fear-potentiated starthe to the auditory and visual CSs, but the trial type $\times$ treatment condition interaction did not reach significance, $F(2,32)=2.62$, $p>0.05$. A significant attenuation of fear-potentiated startle in the anterior perirhinal lesioned rats was revealed from analyzing the difference scores on the auditory CS, $F(1,16)=6.44, p<$ 0.05 , but not on the visual CS trials, $F(1,16)=3.67, p>0.05$. This fear-potentiated startle disruption could not be attributed to changes in startle responsiveness in the lesioned rats, because no effects were obtained from the ANOVA on startle stimulus alone trials, $F(1,16)=0.23, p>0.05$. Reliable fear-potentiated startle on auditory and visual CS trials was found in sham-operated rats ( $p$ values $<0.02$ ), but not in anterior perirhinal lesioned rats ( $p$ values $>0.05$ ). These disruptions could not be attributed to different levels of fear-potentiated startle prior to surgery, because no trial type $\times$ treatment condition interaction or no treatment effects on the difference scores were observed on the prelesion startle test (all $p$ values $>0.05$; data not shown).

From the nine rats undergoing posttraining NMD $\Lambda$ lesions of the anterior perirhinal area, two rats sustained relatively extensive bilateral cell loss in the lateral nucleus of the amygdala, and were therefore excluded from further analyses. In the rats retained for analysis $(n=7)$, the lesions typically produced significant cell loss in the anterior perirhinal area, extending nearly through the entire rostro-caudal extent along the amygdaloid complex. Additional cell loss in the ventral secondary auditory and somatosensory cortices were obtained in many rats. Inconsistent damage to small areas of the lateral part of the lateral nucleus of the amygdala, the dorsal piriform and endopiriform 

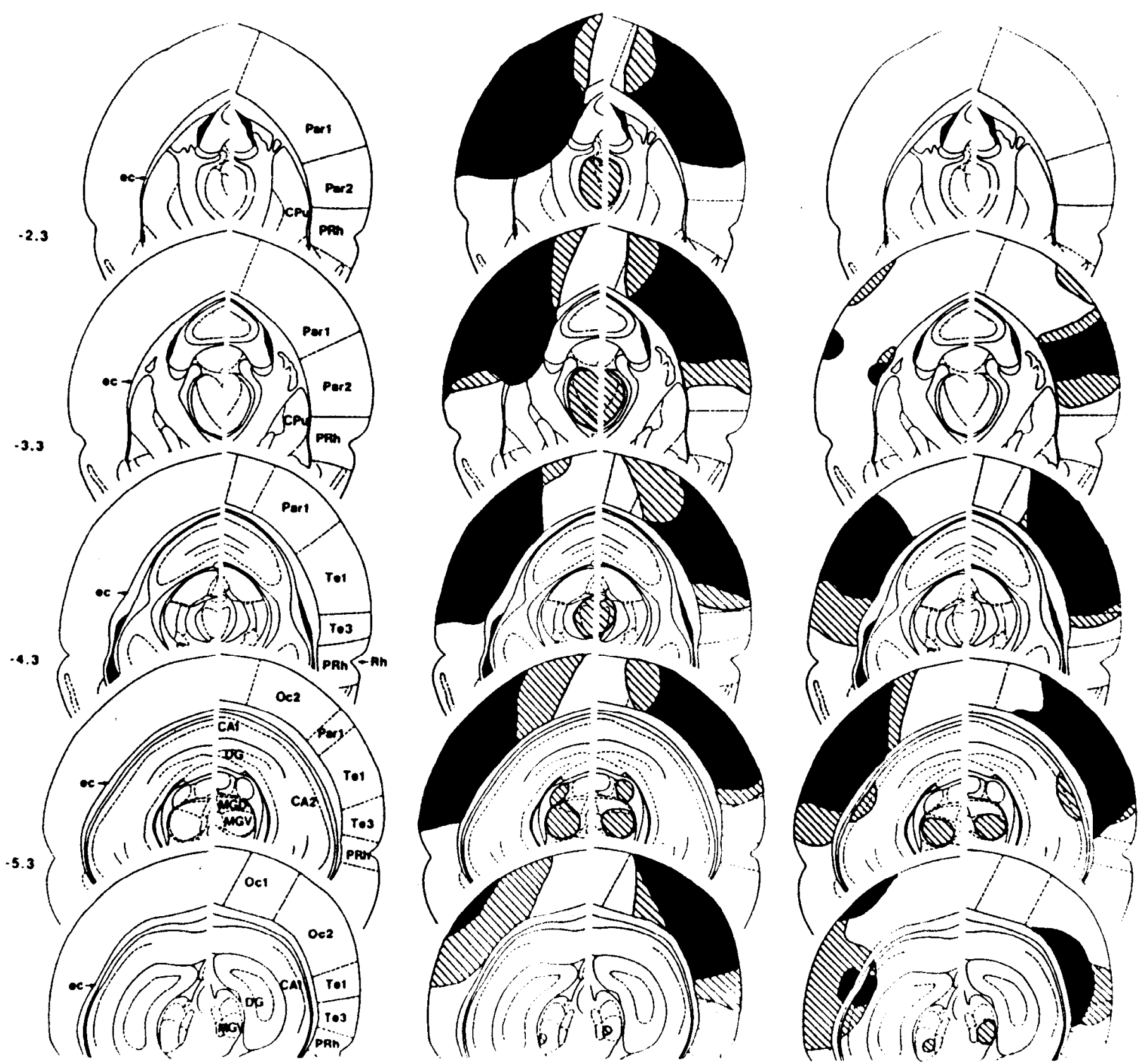

Figure 6. Histological reconstructions of the smallest (black) and largest (hatched) aspiration (center) or NMDA-induced (right) lesions of the auditory cortex. Serial coronal plates through the extent of the auditory cortex are shown on the left. The lateral aspects of each side of the brain with medial aspects removed are shown to conserve space. Note the retrograde neuronal degeneration produced in the rostral ventral division of the medial geniculate body, depicted by hatched areas.

cortices, and parietal cortices were observed in some rats. Figure 8 presents reconstructions of the smallest and largest NMDAinduced lesions of the anterior perirhinal area. Unlike electrolytic lesions, the lower panel of Figure 9 shows that NMDAinduced lesions of the anterior perirhinal cortex did not significantly disrupt fcar-potentiated startle. ANOVAs on the CS difference scores showed no treatment condition effects (all $p$ values $>0.05$ ). Reliable potentiated startle to the auditory and visual CSs was obtained in the sham-operated and lesioned rats (all $p$ values $<0.05$ ), with marginal potentiation to the auditory $\mathrm{CS}$ in lesioned animals, $t(6)=2.31, p<0.06$.

\section{Lesions of the entire perirhinal area}

From the 23 rats undergoing NMDA lesions aimed at the entire perirhinal area, many rats sustained inappropriate lesions, mainly because the lesions invaded significant portions of the lateral nucleus of the amygdala $(n=9)$, and some of them because of significant sparing of the secondary auditory or perirhinal cortices unilaterally or bilaterally $(n=4)$. In the rats retained for analysis $(n=10)$, the lesions typically produced near total cell loss in the perirhinal cortex, and in the secondary auditory cortices. Inconsistent damage to the piriform, endopiriform, and entorhinal cortices, area CA1 of the posterior hippocampus, and 

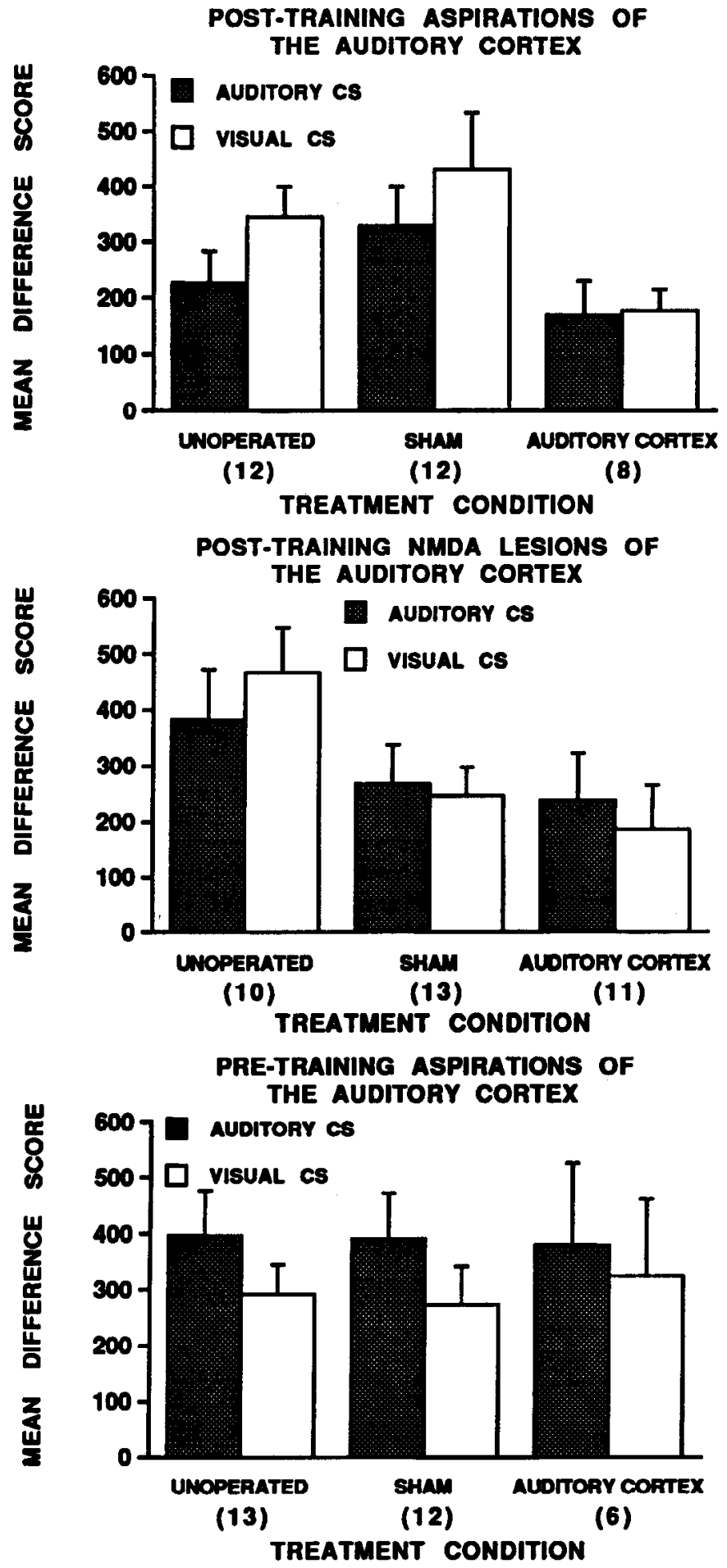

Figure 7. Mean difference scores (+SEM) from auditory and visual CS trials for animals sustaining posttraining aspiration (upper panel), NMDA-induced (middle panel), or pretraining aspiration lesions (lower panel) of the auditory cortex. Mean amplitude startle on the startle stimulus alone trials was 281.3 for unoperated rats, 309.3 for shamoperated rats, and 393.8 for rats sustaining posttraining auditory cortex aspirations. Mean amplitude startle on startle stimulus alone trials was 308.0 for unoperated rats, 319.9 for sham-operated rats, and 335.8 for rats sustaining posttraining NMDA lesions of the auditory cortex. Mean amplitude startle on startle stimulus alone trials was 335.0 for unoperated rats, 300.8 for sham-operated rats, and 324.2 for rats sustaining pretraining auditory cortex aspirations. parietal cortex was also observed. Figure 10 presents reconstructions of the smallest and largest extensive perirhinal area lesions. The upper panel of Figure 11 shows that extensive posttraining NMDA lesions of the perirhinal area produced complete disruption of potentiated startle to the auditory and visual CSs, as indicated by a significant trial type $\times$ treatment condition interaction, $F(4,58)=3.36, p<0.02$. As compared to the controls, perirhinal area lesioned rats showed reliably different potentiated startle to the auditory $\mathrm{CS}, F(2,29)=3.44, p<0.05$, and the visual $\mathrm{CS}, F(2,29)=10.31, p<0.001$. Potentiated startle levels in lesioned rats were different from those of the unoperated and sham-operated rats to either the auditory or visual CS (all $p$ values $<0.05$ ). Unoperated and sham-operated controls demonstrated significant fear-potentiated startle to both CSs ( $p$ values $<0.05$ ), but the lesioned rats failed to demonstrate reliable potentiation to either the auditory $\mathrm{CS}, t(9)=1.07, p>0.05$, or the visual CS, $t(9)=0.70, p>0.05$. The impairment observed in lesioned rats could not be attributed to different startle responsiveness because there were no treatment condition effect on the startle stimulus alone trials, $F(2,29)=0.16, p>0.05$. Likewise, all groups showed similar potentiated startle levels prior to surgery, as indicated by a lack of trial type $\times$ treatment condition interaction on the prelesion test, $F(4,58)=1.07, p>$ 0.05 (data not shown).

From the 20 rats that underwent pretraining perirhinal area NMDA lesions, 8 rats had extensive unilateral or bilateral lesions to the lateral nucleus of the amygdala, or had significant neuronal sparing throughout the perirhinal area $(n=2)$, so these rats were excluded from further analyses. In the rats retained for analysis $(n=10)$, the extent of the lesions was similar to that obtained following extensive posttraining NMDA lesions of the secondary auditory and perirhinal cortex in the preceding experiment. The lower panel of Figure 11 shows that despite an apparent attenuation of fear-potentiated startle in rats sustaining pretraining perirhinal area lesions, this attenuation was not reliable [trial type $\times$ treatment condition interaction, $F(4,70)-$ 1.36, $p>0.05$ ]. No treatment condition effects were detected upon auditory and visual CS difference score analyses $[F(2,35)$ $=2.15$, and $1.62, p$ values $>0.05$, respectively]. Moreover, each treatment condition displayed reliable startle potentiation to each CS (all $p$ values $<0.05$ ).

A possible reason for the apparent lower potentiated startle lcvel observed in the lesioned rats might have been due to their lower reactivity to footshock, as suggested in Table 1. However, an overall ANOVA with shock intensity as a within-subjects factor, and treatment condition as a between-subject variable revealed no overall differences between conditions, $F(2,35)=$ $0.33, p>0.05$, although a near significant interaction was obtained between shock intensity and treatment conditions, $F(8,140)=1.937, p=0.06$. ANOVAs on shock reactivity at intensities apparently most affected did not reveal reliable differences between conditions, $F(2,35)=3.03$ and $0.84, p$ values $>0.05$, for 0.4 and $0.6 \mathrm{~mA}$ shocks, respectively.

\section{Discussion}

Involvement of the auditory thalamus in fear conditioning

Because the basolateral complex of the amygdala is an essential link in a circuit mediating classical fear conditioning to auditory and visual CSs (LeDoux et al., 1990; Sananes and Davis, 1992; Campeau and Davis, 1995), the involvement of some of its afferent inputs were tested in the present experiments. Innervation of the basolateral complex of the amygdala, and more specifi- 
Figure 8. Histological reconstructions of the smallest (black) and largest (hatched) electrolytic (center) and NMDA (right) lesions aimed at the anterior perirhinal area. Serial coronal plates through the extent of the anterior perirhinal area are shown on the left. The lateral aspects of each side of the brain with medial aspects removed are shown to conserve space.
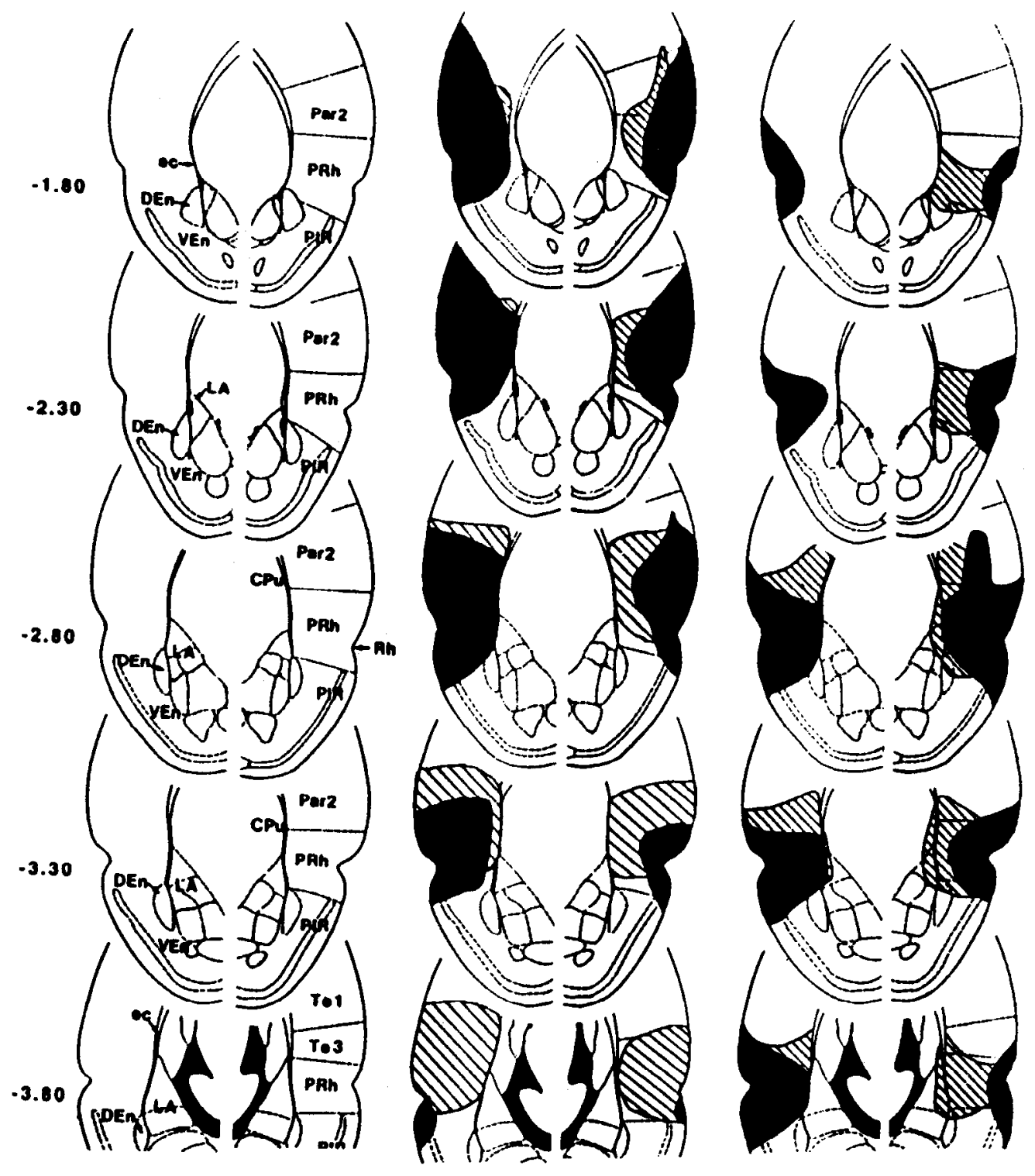

cally the lateral nucleus, includes subcortical afferents from the medial division of the medial geniculate body, the posterior intralaminar nucleus, and the suprageniculate nucleus of the thalamus. Although lesions of the auditory thalamus, including these lateral amygdala afferents, have been shown to be involved in classical fear conditioning to auditory CSs (LeDoux et al., 1984, 1986a,b; Iwata et al., 1986; McCabe et al., 1993), the specificity of the lesion-induced deficits upon the auditory modality has not been established (but see LeDoux et al., 1986b, for instrumental aversive conditioning to visual discriminatory stimuli). This is important because, as discussed in the Introduction, these nuclei are not only involved in auditory functions, but have also been implicated in somatosensory and visual information processing (Peschanski et al., 1981; LeDoux et al., 1985, 1987; Hicks et al., 1986; Cruikshank et al., 1992). In the present studies, complete electrolytic or excitotoxic lesions of the entire auditory thalamus specifically disrupted fear-potentiated startle to the auditory CS, whether the lesions were made before or after conditioning. This outcome supports the prior findings of LeDoux and collaborators (1984, 1986a,b; Iwata et al., 1986), and demonstrates the necessity of the auditory thalamus in fear condi- tioning, specifically to auditory stimuli, using classical conditioning procedures.

The results also indicate that the medial division of the medial geniculate body and posterior intralaminar nucleus are not necessary for transmission of somatosensory information initiated by shock delivery, because rats lesioned before training showed conditioned fear to the visual CS. However, a negative finding using lesion techniques does not preclude the involvement of these nuclei, in conjunction with other structures, in the transmission of somatosensory information induced by footshock (Cruikshank et al., 1992).

The outcome obtained after more selective auditory thalamic lesions indicated that only posttraining lesions to the ventral and dorsal divisions of the medial geniculate body, which innervate the lateral nucleus of the amygdala after one or more cortical relays, specifically disrupted fear-potentiated startle to the auditory CS. In contrast, if anything, rats with lesions of the medial division of the medial geniculate body, posterior intralaminar, and suprageniculate nuclei displayed higher levels of fear-potentiated startle, especially to the auditory CS. Hence, these data suggest that the afferents originating from the ventral and dorsal 

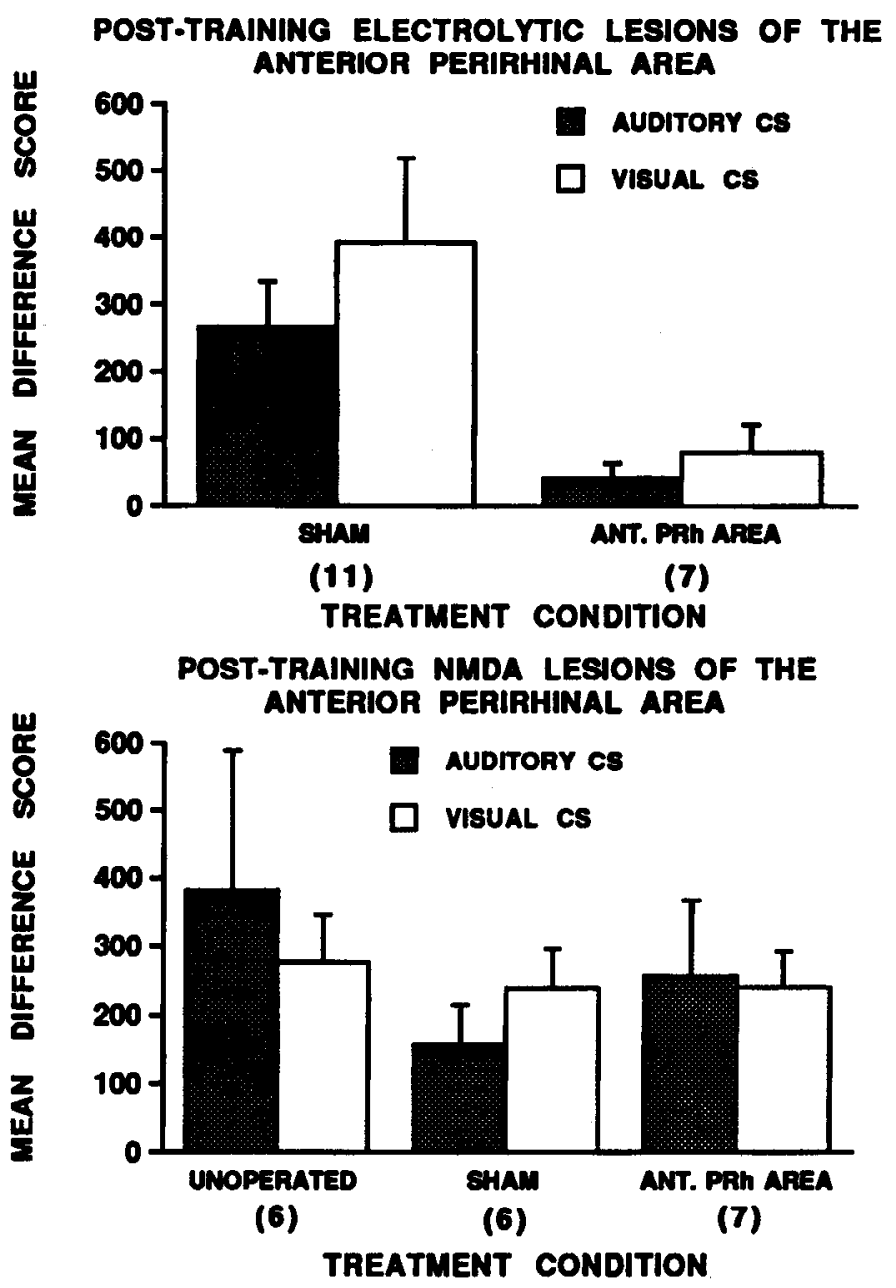

Figure 9. Mean difference scores (+SEM) from auditory and visual CS trials for animals sustaining posttraining electrolytic (upper panel) or NMDA-induced (lower panel) lesions of the anterior perirhinal arca. Mean amplitude startle on startle stimulus alone trials was 303.0 for sham-operated rats, and $\mathbf{2 7 9 . 2}$ for rats sustaining relatively complete posttraining electrolytic lesions of the anterior perirhinal area. Mean amplitude startle on the startle stimulus alone trials was 261.2 for unoperated rats, 272.2 for sham-operated rats, and 345.4 for rats sustaining posttraining NMDA lesions of the anterior perirhinal area.

divisions of the medial geniculate body are involved in the expression of fear-potentiated startle to an auditory CS. Afferents originating from the posterior auditory thalamic nuclei also appear to be involved in fear-potentiated startle to an auditory CS, but only after injury to the ventral and dorsal divisions of the medial geniculate body, as suggested by the significant levels of fear-potentiated startle after retraining in rats previously given ventral and dorsal medial geniculate body lesions. However, an important limitation to the proposal of the involvement of the ventral and dorsal divisions of the medial geniculate body in auditory fear conditioning involves the possibility that destruction of even a few neurons of the posterior auditory thalamic nuclei, in combination with lesions of the MGV and MGD, might be responsible for the disruption observed. This possibility cannot be entirely ruled out with the present results.

The disruptive effect of ventral and dorsal divisions lesions is, in part, different from the results of Jarrell et al. (1987), who observed, in rabbits, no effects of lesions limited to the ventral division of the medial geniculate body on differential bradycar- diac conditioning. Inclusion of the dorsal division in the present lesions, or species differences in the connectivity between the thalamus and forebrain, might underlie these differences. The lack of disruptive effects of posterior auditory thalamic lesions is consistent with the results of Romanski and LeDoux (1992a,b) with somatomotor and cardiovascular conditioned responses to auditory CSs in rats, but is different from the results of McCabe et al. (1993), who observed disruption of conditioned bradycardiac responses to auditory CSs by lesions of the medial division of the medial geniculate body in rabbits. At the present time, it is not clear why different outcome are obtained between the present studies, and those of Romanski and LeDoux with rats on the one hand, and those of Jarrell, McCabe, and coworkers with rabbits on the other hand, after relatively discrete lesions involving the MGM.

\section{Involvement of the primary auditory cortex in fear conditioning}

Pre- or posttraining auditory cortex aspirations, mostly restricted to the primary auditory area, as revealed by retrograde degeneration of the ventral division of the medial geniculate body, did not reliably disrupt fear-potentiated startle. The unreliable attenuation of fear-potentiated startle observed after posttraining lesions was not specific to the auditory CS, or to the lesioned rats, and was less pronounced when the more restricted excitotoxic lesions were used. Thus, part of the attenuation obtained to the auditory, and perhaps, to the visual CS, could be attributed to the surgical procedures alone. Hence, these results suggest that the primary auditory cortex is not necessary for fear-potentiated startle to auditory CSs, and is consistent with other classical fear conditioning studies (LeDoux et al., 1984; Jarrell et al., 1987; Teich et al., 1988; Romanski and LeDoux, 1992a,b). By default then, the present results suggest the involvement, in fear-potentiated startle, of the secondary auditory and/or dorsal perirhinal cortices, which are innervated by the dorsal division of the medial geniculate body (Guldin and Markowitsch, 1983; Arnault and Roger, 1990; LeDoux et al., 1991a).

\section{Involvement of secondary auditory and perirhinal cortices in fear conditioning}

The hypothesis that secondary auditory and perirhinal cortices are involved in fear conditioning was supported, in part, by the posttraining lesions, which completely blocked fear-potentiated startle to the auditory, and also, to the visual CS. These findings are thus consistent with the deficits obtained in cats following combined posttraining primary, secondary auditory, and perirhinal cortices lesions in auditory signaled avoidance instrumental tasks (see Neff et al., 1975). In addition, deficits in avoidance tasks have been obtained with lesions restricted to the perirhinal cortex (Colavita and Weisberg, 1979), and are observed to complex patterned CSs in the auditory, visual, and somatosensory modalities (Colavita, 1972, 1974).

Importantly, pretraining secondary auditory and perirhinal cortices lesions did not reliably disrupt fear-potentiated startle to either CS. This is consistent with the lack of effect of pretraining temporal cortical lesions which included the perirhinal cortex, upon auditory fear conditioning (DiCara et al., 1970; Romanski and LeDoux, 1992a,b). In the present studies, the differences observed between pre- and posttraining lesions did not arise from differences in lesion size, because the extent of the lesions in each study was similar. Also, the posttraining lesion deficits were observed only when excitotoxic lesions included most of 
Figure 10. Histological reconstructions of the smallest (black) and largest (hatched) extensive NMDA lesions of the perirhinal area. Serial coronal plates through the extent of the perirhinal area are shown on the left. The lateral asdial aspects removed are shown to conserve space. pects of each side of the brain with me-
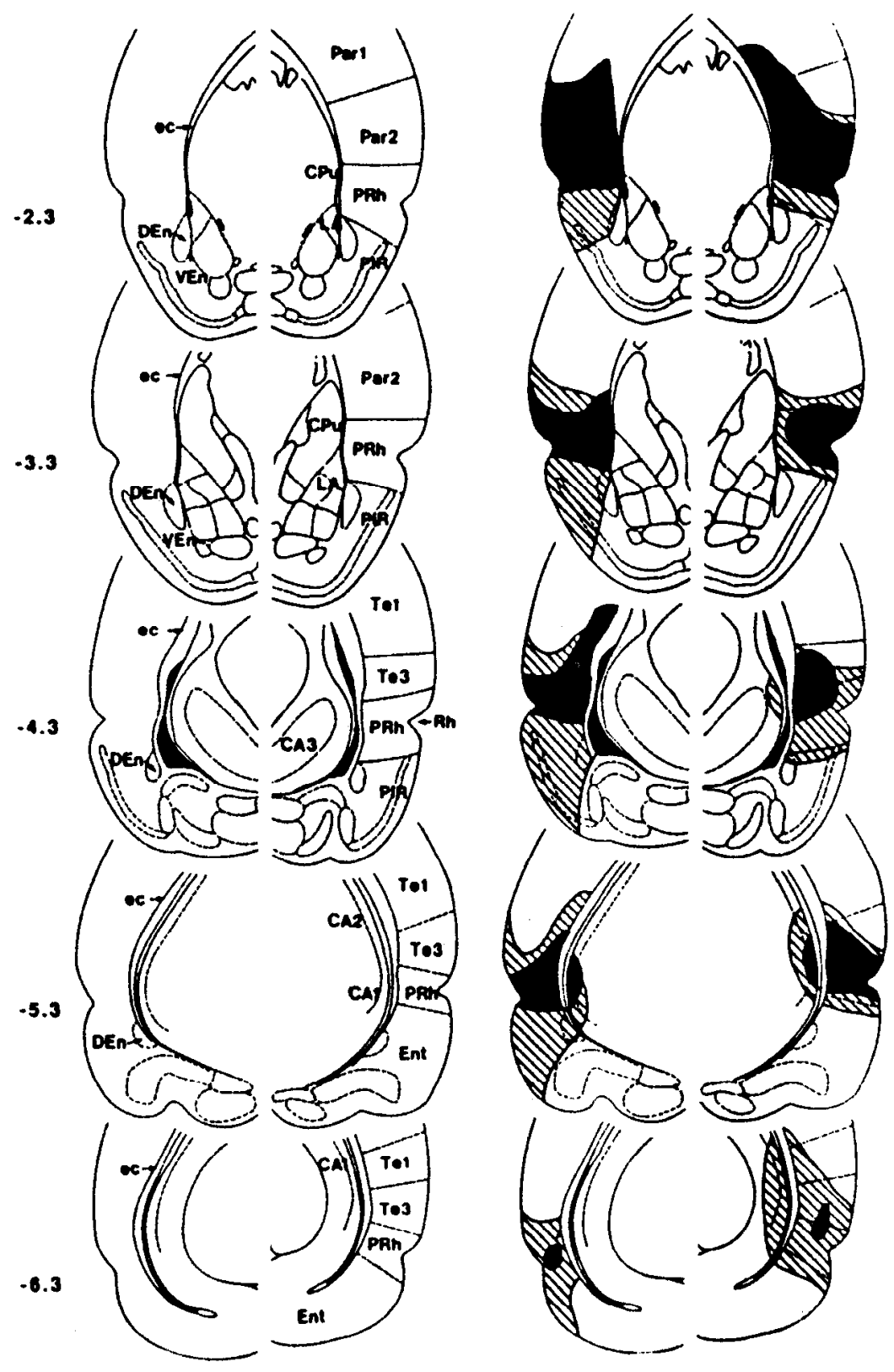

the rostro-caudal extent of the perirhinal area. Although these results are consistent with those of Rosen et al. (1992), they do not support the Rosen et al. conclusion that the anterior part of the perirhinal cortex is mainly involved in fear-potentiated startle. Anterior perirhinal area lesions disrupted fear-potentiated startle to auditory and visual CSs only after electrolytic, but not after equally extensive excitotoxic lesions. This difference might be explained by the probable electrolytically induced destruction of external capsule fibers coming from the thalamus on their way to the posterior secondary auditory and dorsal perirhinal cortices, and/or the destruction of fibers coursing from these cortices to the lateral nucleus of the amygdala, which would be spared by excitotoxic lesions.

Because of the proximity of the lateral nucleus of the amygdala, lesions of which block fear-potentiatcd startle (Campeau and Davis, 1995), an important issue is whether lesions of the secondary and perirhinal cortices significantly encroached upon the lateral nucleus, which might account for the deficits ob- served. Although possible, this is unlikely because rats sustaining anterior perirhinal area damage, showing as large, if not larger, neuronal loss in the lateral nucleus of the amygdala, displayed reliable fear-potentiated startle. This suggests that the intended lesions to the secondary auditory and perirhinal cortices, but not the collateral damage to the lateral nucleus of the amygdala, in some rats, was responsible for the disruption of fearpotentiated startle to the auditory and visual CSs.

\section{Interpretations, limitations, and proposed directions}

Overall, the present series of experiments indicates that the auditory thalamus, through either its direct or indirect amygdaloid projections, is necessary and specifically involved in the mediation of fear-potentiated startle to auditory conditioned stimuli, consistent with its involvement in auditory fear conditioning in general (LeDoux et al., 1984, 1986a,b; Iwata et al., 1986). The results also suggest that the ventral and dorsal divisions of the medial geniculate body might specifically be involved in audi- 
EXTENSIVE POST-TRAINING NMDA LESIONS OF THE PERIRHINAL AREA

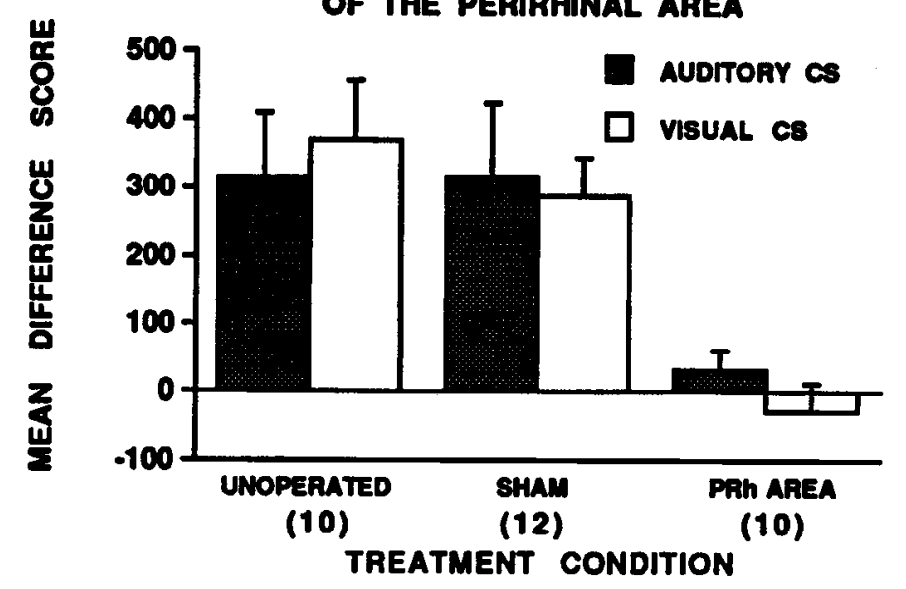

EXTENSIVE PRE-TRAINING NMDA LESIONS OF THE PERIRHINAL AREA

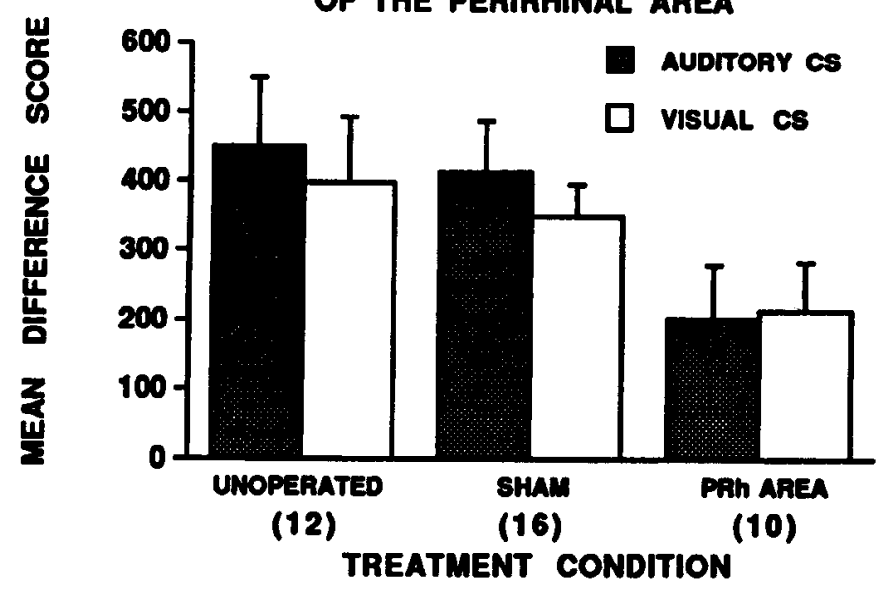

Figure 11. Mean difference scores (+SEM) from auditory and visual CS trials for animals sustaining extensive posttraining (upper panel), or pretraining (lower panel) NMDA lesions of the perirhinal area. Mean amplitude startle on the startle stimulus alone trials was 323.1 for unoperated rats, 319.8 for sham-operated rats, and 350.1 for rats sustaining extensive posttraining NMDA lesions of the perirhinal area. Mean amplitude startle on the startle stimulus alone trials was 427.3 for unoperated rats, 360.5 for sham-operated rats, and 281.7 for rats sustaining extensive pretraining NMDA lesions of the perirhinal area.

tory fear conditioning, but this conclusion needs to await proof that the deficits observed following posttraining lesions were not due to concomitant damage to neurons of the medially located posterior auditory thalamic nuclei (MGM, PIL, and SG).

The lack of modality-specific disruption by the present posttraining secondary and perirhinal cortical lesions could be interpreted in at least two general ways. First, it is possible that the cortical areas lesioned might be involved in some general learning processes such as information storage or retrieval, thus explaining the lack of modality specificity of the lesions. In fact, deficits following posttraining cortical lesions have traditionally been interpreted as affecting either the perceptual capacity, associative substrate (engram), or memory retrieval processes (see Neff et al., 1975, and Meyer and Meyer, 1977, for reviews). The present lack of modality-specific disruption obtained only with posttraining cortical lesions suggests the likelihood of any of these interpretations.

Nonspecific factors, independent of any learning processes, cannot, likewise, be ruled out entirely. The fact that rostral (pres- ent results), or caudal perirhinal area lesions alone (Rosen et al., 1992) do not disrupt fear-potentiated startle, whereas lesions of its entire rostro-caudal extent do, could be interpreted as a mass action cffect, which produces increasing disruption with increasing amount of tissue lesioned, independent of the cortical area damaged (see Lashley, 1950). In fact, the trend toward attenuation of both auditory and visual fear-potentiated startle by large posttraining primary auditory cortex aspirations in the present study may be suggestive of a nonspecific mass action effect. However, previous work in this laboratory has indicated that extensive posttraining aspirations of primary and secondary visual cortices, as well as other cortical areas (frontal, medial prefrontal, and insular cortices) which were as large, if not larger, than the extensive perirhinal area lesions reported here, did not disrupt fear-potentiated startle to a visual CS (Rosen et al., 1992; Falls and Davis, 1993). These data suggest that a simple mass action effect may not account entirely for the deficits induced by the present perirhinal area lesions.

Another nonspecific effect that could have reduced fear-potentiated startle might have resulted from deafferentation or cell death in the lateral nucleus of the amygdala produced by increasingly large cortical lesions of cells that directly innervate this nucleus. Retraining lesioned rats under conditions where the rate of reacquisition of fear-potentiated startle (Kim and Davis, 1993) can be compared, or reversal conditioning to assess retention based on retardation of conditioning to the opposite CS, might be useful tools to more exactly determine the deficit displayed by rats given secondary and perirhinal cortical lesions.

The second general possibility is that the conditioning deficit induced by the cortical areas lesioned in the present study represents their involvement in the transmission of stimulus information to the amygdala. Disruption of fear-potentiated startle to the auditory and visual CSs might reflect the fact that some of the cortical areas which were always included in the lesions ( $\mathrm{Te} 2$ and the perirhinal cortex) receive auditory as well as visual information, which can then be transmitted to the amygdala (see introductory remarks). Discrete lesions of all the cortical areas damaged in the present study ( $\mathrm{Te} 2, \mathrm{Te} 3$, and the perirhinal cortex) will be required to determine whether polymodal or unimodal deficits can be obtained. The possibility remains that posttraining lesions limited to Te3, which is reported to exclusively receive auditory inputs (Romanski and LeDoux, 1993b), might specifically disrupt fear-potentiated startlc to an auditory CS.

Regarding this later possibility, it is important to point out that the dorsal division of the medial geniculate body might be specifically involved in fear conditioning to auditory stimuli. This is based on the indirect evidence obtained in the present studies that combined lesions of the dorsal and ventral divisions of the medial geniculate body completely blocked fear-potentiated startle to the auditory CS whereas lesions of the auditory cortex, which receives input primarily from the ventral division of the medial geniculate body, did not. Anatomical data indicate that the dorsal division of the medial geniculate body projects to secondary auditory areas ( $\mathrm{Te} 2$ and $\mathrm{Te} 3$ ), and perhaps to the perirhinal cortex, but only its dorsal aspect at and above the rhinal fissure (Guldin and Markowitsch, 1983; Arnault and Roger, 1990; LeDoux et al., 1991a). However, in rats, even this dorsal perirhinal projection from the dorsal division of the medial geniculate body, as contrasted to the projection of the adjacent suprageniculate nucleus, has not been clearly established because each of the above studies have employed cortical tracer deposits, making it difficult to determine the extent of tracer 
spread in the perirhinal or secondary auditory cortex, respectively. Thus, anterograde tracing specifically from the dorsal division of the medial geniculate body would be required to resolve its exact cortical terminal field.

Physiologically, the rostral aspect of the dorsal division of the medial geniculate body displays characteristics that might be consistent with a role as a putative auditory transmission pathway. In the cat, which is the species in which the most extensive electrophysiological recordings have been carried out in the medial geniculate body, units of the dorsal division tend to display relatively broad tuning curves, respond to noises rather than to pure tones more readily, and have variable response latencies, which are on average longer than those observed in the ventral division (Calford and Webster, 1981; Calford, 1983; Calford and Aitkin, 1983; Morel et al., 1987; Aitkin, 1990). Although these characteristics are not optimal for fast and accurate transmission of auditory information, particularly as compared with those of the ventral division of the medial geniculate body, they are suggestive of a significant amount of auditory convergence at the level of the dorsal division. Such auditory information convergence might be important for an organism to detect a broad range of acoustic danger signals, and thus elaborate appropriate behavioral responses. Also consistent with a role in fear conditioning are the observations of Edeline and Weinberger (1991a) that units of the dorsal division of the guinea pig medial geniculate body show durable receptive field plasticity after aversive conditioning, an effect that is observed only transiently in the ventral division (Edeline and Weinberger, 1991b). Specific lesions of the dorsal division of the medial geniculate body, and additional electrophysiological recordings of this area, will be required to test directly its involvement in auditory fear conditioning.

Hence, the present data are consistent with multiple interpretations of the role of the secondary auditory and perirhinal cortices in fear conditioning. As stated above, additional anatomical, physiological, and behavioral studies will be required to determine the exact function(s) of the dorsal division of the medial geniculate body, secondary auditory and perirhinal cortices in fear conditioning.

\section{Appendix}

\section{Abbreviations}

APT

anterior pretectal nucleus

CA1 CA2, CA3 hippocampal subdivisions

$\mathrm{CPu}$

DEn

DG

DLG

ec

Ent

GP

LA

LP

MGD

MGM

MGV

ml

Oc1 Oc2

opt

Par1 Par2

PIL

PIR

Pot
PP
PRh
Rh
SG
SN
SPFPC
Te1
Te2 Te3
VEn
VLG

\section{References}

Aitkin L (1990) The auditory cortex. London: Chapman \& Hall.

Arnault P, Roger M (1990) Ventral temporal cortex in the rat: connections of sccondary auditory areas $\mathrm{Te} 2$ and Te3. J Comp Neurol 302: 110-123.

Brown JS, Kalish HI, Farber IE (1951) Conditioned fear as revealed by magnitude of startle response to an auditory stimulus. J Exp Psychol 41:317-328.

Calford MB (1983) The parcellation of the medial geniculate body of the cat defined by the auditory response properties of single units. J Neurosci 3:2350-2364.

Calford MB, Aitkin LM (1983) Ascending projections to the medial geniculate body of the cat: evidence for multiple, parallel auditory pathways through thalamus. J Neurosci 3:2365-2380.

Calford MB, Webster WR (1981) Auditory representation within principal division of cat medial geniculate body: an electrophysiological study. J Neurophysiol 45:1013-1028.

Campeau S, Davis M (1992) Fear potentiation of the acoustic startle reflex using noises of various spectral frequencies as conditioned stimuli. Animal Learning Behav 20:177-186.

Campeau S, Davis M (1995) Involvement of the central nucleus and basolateral complex of the amygdala in fear conditioning measured with fear-potentiated startle in rats trained concurrently with auditory and visual conditioning. J Neurosci 15:2301-2311.

Campeau S, Liang KC, Davis M (1990) Long-term retention of fearpotentiated startle following a short training session. Animal Learning Behav 18:462-468.

Cassella JV, Davis M (1986) The design and calibration of a startle measurement system. Physiol Behav 36:377-383.

Clerici WJ, Coleman JR (1990) Anatomy of the rat medial geniculate body. I. Cytoarchitecture, myeloarchitecture, and neocortical connectivity. J Comp Neurol 297:14-31.

Colavita FB (1972) Auditory cortical lesions and visual pattern discrimination in cat. Brain Res 39:437-447.

Colavita FB (1974) Insular-temporal lesions and vibrotactile temporal pattern discrimination in cats. Physiol Behav 12:215-218.

Colavita FB, Weisberg DH (1979) Insular cortex and perception of temporal patterns. Physiol Behav 22:827-830.

Coleman J, Clerici WJ (1980) Extrastriate projections from thalamus to posterior occipital-temporal cortex in the rat. Brain Res 194:205209.

Cruikshank SJ, Edeline J-M, Weinberger NM (1992) Stimulation at a site of auditory-somatosensory convergence in the medial geniculate nucleus is an effective unconditioned stimulus for fear conditioning. Behav Neurosci 106:471-483.

Deacon TW, Eichenbaum H, Rosenberg P, Ecknamm KW (1983) Afferent connections of the perirhinal cortex in the rat. J Comp Neurol 220:168-190.

De Olmos J, Alheid GF, Beltramino CA (1985) Ainygdala. In: The rat nervous system, Vol 1 , Forebrain and midbrain (Paxinos G, ed), pp 223-334. Orlando: Academic.

DiCara LV, Braun JJ, Pappas BA (1970) Classical conditioning and instrumental learning of cardiac and gastrointestinal responses following removal of neocortex in the rat. J Comp Physiol Psychol 73: 208-216.

Edeline J-M, Weinberger NM (1991a) Subcortical adaptive filtering in the auditory system: associative receptive field plasticity in the dorsal medial geniculate body. Behav Neurosci 105:154-175.

Edeline J-M, Weinberger NM (1991b) Thalamic short-term plasticity in the auditory system: associative retuning of receptive fields in the ventral medial geniculate body. Behav Neurosci 105:618-639. 
Fallon JH, Benevento LA (1977) Auditory-visual interaction in cat orbito-insular cortex. Neurosci Lett 6:143-149.

Falls WA, Davis M (1993) Visual cortex ablations do not prevent extinction of fear-potentiated startle using a visual conditioned stimulus. Behav Neural Biol 60:259-270.

Guldin WO, Markowitsch HJ (1983) Cortical and thalamic afferent connections of the insular and adjacent cortex of the rat. J Comp Neurol 215:135-153.

Hicks TP, Stark CA, Fletcher WA (1986) Origins of afferents to visual suprageniculate nucleus of the cat. J Comp Neurol 246:544-554.

Iwata J, LeDoux JE, Meeley MP, Arneric S, Reis DJ (1986) Intrinsic neurons in the amygdaloid field projected to by the medial geniculate body mediate emotional responses conditioned to acoustic stimuli. Brain Res 383:195-214.

Jarrell TW, Gentile CG, McCabe PM, Schneiderman N (1986a) The role of the medial geniculate region in differential Pavlovian conditioning of bradycardia in rabbits. Brain Res 374:126-136.

Jarrell TW, Romanski LM, Gentile CG, McCabe PM, Schneiderman N (1986b) Ibotenic acid lesions in the medial geniculate region prevent the acquisition of differential Pavlovian conditioning of bradycardia to acoustic stimuli in rabbits. Brain Res 382:199-203.

Jarrell TW, Gentile CG, Romanski LM, McCabe PM, Schneiderman N (1987) Involvement of cortical and thalamic auditory regions in retention of differential bradycardiac conditioning to acoustic conditioned stimuli in rabbits. Brain Res 412:285-294.

Kim M, Davis M (1993) Lack of a temporal gradient of retrograde amnesia in rats with amygdala lesions assessed with the fear-potentiated startle paradigm. Behav Neurosci 107:1088-1092.

Lashley KS (1950) In search of the engram. In: Symposium of the society for experimental biology, No IV, Physiological mechanisms in animal behavior, pp 454-483. New York: Academic

LeDoux JE, Sakaguchi A, Reis DJ (1984) Subcortical efferent projections of the medial geniculate nucleus mediate emotional responses conditioned to acoustic stimuli. J Neurosci 4:683-698.

LeDoux JE, Ruggiero DA, Reis DJ (1985) Projections to the subcortical forebrain from anatomically defined regions of the medial geniculate body in the rat. J Comp Neurol 242:182-213.

LeDoux JE, Sakaguchi A, Iwata J, Reis DJ (1986a) Interruption of projections from the medial geniculate body to an archi-neostriatal field disrupts the classical conditioning of emotional responses to acoustic stimuli. Neuroscience 17:615-627.

LeDoux JE, Iwata J, Pearl D, Reis DJ (1986b) Dismption of auditory but not visual learning by destruction of intrinsic neurons in the medial geniculate body of the rat. Brain Res 371:395-399.

LeDoux JE, Ruggiero DA, Forest R, Stornetta R, Reis DJ (1987) Topographic organization of convergent projections to the thalamus from the inferior colliculus and spinal cord in the rat. J Comp Neurol 264:123-146.

LeDoux JE, Farb C, Ruggiero DA (1990a) Topographic organization of neurons in the acoustic thalamus that project to the amygdala. $J$ Neurosci 10:1043-1054.

LeDoux JE, Cicchetti P, Xagoraris A, Romanski LM (1990b) The lateral amygdaloid nucleus: sensory interface of the amygdala in fear conditioning. J Neurosci 10:1062-1069.

LeDoux JE, Farb CR, Romanski LM (1991a) Overlapping projections to the amygdala and striatum from auditory processing areas of the thalamus and cortex. Neurosci Lett 134:139-144.

LeDoux JE, Farb CR, Milner TA (1991b) Ultrastructure and synaptic associations of auditory thalamo-amygdala projections in the rat. Exp Brain Res 85:577-586.

Loe PR, Benevento LA (1969) Auditory-visual interaction in single units in the orbito-insular cortex of the cat. Electroencephalogr Clin Neurophysiol 26:395-398.

Mascagni F, McDonald AJ, Coleman JR (1993) Corticoamygdaloid and corticocortical projections of the rat temporal cortex: a Phaseolus vulgaris leucoagglutinin study. Neuroscience 57:697-715.

McCabe PM, McEchron MD, Green EJ, Schneiderman N (1993) Electrolytic and ibotenic acid lesions of the medial subnucleus of the medial geniculate prevent the acquisition of classically conditioned heart rate to a single acoustic stimulus in rabbits. Brain Res 619:291298.

McDonald AJ, Jackson TR (1987) Amygdaloid connections with posterior insular and temporal cortical areas in the rat. J Comp Neurol 262:59-77.

Meyer DR, Meyer PM (1977) Dynamics and bases of recoveries of functions after injuries to the cerebral cortex. Physiol Psychol 5:133165.

Morel A, Rouiller E, de Ribaupierre Y, de Ribaupierre F (1987) Tonotopic organization in the medial geniculate body (MGB) of lightly anesthetized cats. Exp Brain Res 69:24-42.

Neff WD, Diamond IT, Casseday JH (1975) Behavioral studies of auditory discrimination: central nervous system. In: Handbook of sensory physiology, Vol 2, Auditory system. Physiology (CNS). Behavioral studies of psychoacoustics (Keidel WD, Neff WD, eds), pp 307400. Berlin: Springer.

Ottersen OP (1982) Connections of the amygdala of the rat. IV. Corticoamygdaloid and intraamygdaloid connections as studied with ax onal transport of horseradish peroxidase. J Comp Neurol 205:30-48.

Ottersen OP, Ben-Ari Y (1979) Afferent connections to the amygdaloid complex of the rat and cat. I. Projections from the thalamus. J Comp Neurol 187:401-424.

Paxinos G, Watson C (1986) The rat brain in stereotaxic coordinates, 2d ed. Orlando: Academic.

Peschanski M, Mantyh PW, Besson J-M (1981) Posterior intralaminar region in rat: neuronal responses to noxious and nonnoxious cutaneous stimuli. Exp Neurol 72:226-238.

Robinson CJ, Burton H (1980) Somatic submodality distribution within the second somatosensory (SII), 7b, retroinsular, postauditory, and granular insular cortical areas of $M$. fascicularis. J Comp Neurol 192: 93-108.

Roger M, Arnault P (1989) Anatomical study of the connections of the primary auditory area in the rat. J Comp Neurol 287:339-356.

Romanski LM, LeDoux JE (1992a) Equipotentiality of thalamo-amygdala and thalamo-cortico-amygdala circuits in auditory fear conditioning. J Neurosci 12:4501-4509.

Romanski LM, LeDoux JE (1992b) Bilateral destruction of neocortical and perirhinal projection targets of the acoustic thalamus does not disrupt auditory fear conditioning. Neurosci Lett 142:228-232.

Romanski LM, LeDoux JE (1993a) Organization of rodent auditory cortex: anterograde transport of PHA-L from MGv to temporal neocortex. Cereb Cortex 3:499-514.

Romanski LM, LeDoux JE (1993b) Information cascade from primary auditory cortex to the amygdala: corticocortical and corticoamygdaloid projections of temporal cortex in the rat. Cereb Cortex 3:515532.

Rosen JB, Hitchcock JM, Miserendino MJD, Falls WA, Campeau S, Davis M (1992) Lesions of the perirhinal cortex, but not of the frontal, medial pre-frontal, visual or insular cortex block fear-potentiated startle using a visual conditioned stimulus. J Neurosci 12:4624 4633.

Ryugo DK, Killackey HP (1974) Differential telencephalic projections of the medial and ventral divisions of the medial geniculate body of the rat. Brain Res 82:173-177.

Sally SL, Kelly JB (1988) Organization of auditory cortex in the albino rat: sound frequency. J Neurophysiol 59:1627-1638.

Sananes CB, Davis M (1992) N-Methyl-D-aspartate lesions of the lateral and basolateral nuclei of the amygdala block fear-potentiated startle and shock sensitization of startle. Behav Neurosci 106:72-80.

Teich AH, McCabe PM, Gentile CG, Jarrell TW, Winters RW, Liskowsky DR, Schneiderman N (1988) Role of auditory cortex in the acquisition of differential heart rate conditioning. Physiol Behav 44: 405-412.

Turner BH, Herkenham M (1981) An autoradiographic study of thalamo-amygdaloid connections in the rat. Anat Rec 199:260A.

Turner BH, Herkenham M (1991) Thalamoamygdaloid projections in the rat: a test of the amygdala's role in sensory processing. J Comp Neurol 313:295-325.

Turner BH, Zimmer J (1984) The architecture and some of the interconnections of the rat's amygdala and lateral periallocortex. J Comp Neurol 227:540-557.

Veening JG (1978a) Cortical afferents of the amygdaloid complex in the rat: an HRP study. Neurosci Lett 8:191-195.

Veening J (1978b) Subcortical afferents of the amygdaloid complex in the rat: an HRP study. Neurosci Lett 8:197-202.

Wakefield C (1980) The topographical organization and laminar origin of some cortico-amygdaloid connections. Neurosci Lett 20:21-24.

Winer JA, Larue DT (1987) Patterns of reciprocity in auditory thalamocortical and corticothalamic connections: study with horseradish peroxidase to the medial geniculate body and posterior thalamic nuclei. J Comp Neurol 257:282-315. 